\title{
LA VOZ DE LOS MUERTOS DE CARMEN DE BURGOS (1911), ENTRE SIGLOS, LENGUAS Y CULTURAS
}

ANA VIAN HERRERO

Instituto Universitario Menéndez Pidal (UCM) avihe@filol.ucm.es

RESUMEN: Los trece diálogos que incluye Carmen de Burgos en su obra literaria La voz de los muertos (Valencia, 1911) son piezas maestras del lucianismo dialógico de inicios del siglo XX. Se analizan aquí las relaciones literarias que la autora establece con sus modelos declarados (Sócrates, Platón, Parini, Leopardi) y con otros que, aunque no se mencionen explícitamente (Luciano, Fontenelle, Voltaire), son imprescindibles para comprender los cambios ideológicos y estéticos de esta tradición dialógica milenaria a la altura de la Edad de Plata.

PALABRAS CLAVE: Carmen de Burgos, La voz de los muertos, lucianismo, diálogos de muertos, Fontenelle, Voltaire, Parini, Leopardi. 


\section{LA VOZ DE LOS MUERTOS OF CARMEN DE BURGOS (1911), Across Centuries, Languages and Cultures}

ABSTRACT: The thirteen dialogues included by Carmen de Burgos in her literary work La voz de los muertos (Valencia, 1911) are masterpieces of lucianist dialogue at the beginning of the $\mathrm{XX}^{\text {th }}$ century. This paper discusses the literary relationship that the author established with her declared models (Socrates, Platon, Parini, Leopardi) and with other references that, although not explicitly mentioned (Lucian, Fontenelle, Voltaire) are essential to undestand the ideological and aesthetic changes of this millenarian dialogic tradition during the spanish "Edad de Plata".

KEY WORDS: Carmen de Burgos, La voz de los muertos, lucianism, dialogues of the dead., Fontenelle, Voltaire, Parini, Leopardi.

Zn el "Diálogo entre la Autora y su Genio Familiar", preliminar de $L a$ Cvoz de los muertos, se lee este intercambio sobre la condición de los interlocutores:

A.-Son sombras, y hablan con la serenidad augusta de allende

la tumba.

G. - ¿Y las vivas?

A.-Las imitan... (Burgos [1911]: 9) ${ }^{1}$.

${ }^{1}$ Este trabajo se ha realizado en el marco del proyecto FFI2015-63703-P, con sede en el Instituto Universitario Menéndez Pidal. Todas las citas entre paréntesis en cuerpo de texto remiten a la ed. de Valencia, Sempere y Cía, s.a., asequible en: bdh-rd.bne. es/viewer.vm?id=0000076007 \&page $=1$. Suele considerarse como fehaciente la fecha de 1911. La publicación coincide con el momento en que Carmen de Burgos obtiene una plaza de profesora numeraria en la Escuela Normal Central de Maestras (Sección de Letras) y con varios de sus viajes por Europa. Prometeo reedita el texto en 1918, es decir, fue una lectura de cierto éxito. La que suscribe, junto a María Jesús Fraga, han editado la parte correspondiente a los diálogos, que se halla en prensa en Editoria Torremozas (con fecha prevista de salida en la primavera de 2018), en cuya intro-
Y, enseguida, este otro sobre la tradición dialógica a la que quiere la autora que la adscriban:

G-.-Estos diálogos me traen un vago recuerdo de verdades enunciadas por Sócrates, Platón, Leopardi, Parini...

[...]

G.- ¿Y si dicen que los imitaste?

A.-—Qué importa! Si la parodia grotesca recuerda la obra inmortal, no ha faltado arte al autor de la parodia. Si los genios nos dejaron sus ideas, ¿qué mal hay en que fructifiquen? (Burgos, [1911]: 10).

La Voz de los muertos es una obra genéricamente miscelánea, que reúne una "Primera parte" de trece diálogos y una "Segunda parte", menor en alcance y extensión, de dramas en prosa que la autora califica como "Teatro irrepresentable" y probablemente corresponden a otro tiempo creativo $^{2}$. Aquí me ocupo solo de la primera, la de más hondura y calidad literaria, y la menos estudiada en algunos aspectos de mucho interés ${ }^{3}$. Me

ducción se han incluido sumarísimamente las principales ideas aquí desarrolladas. 2 Solo Núñez Rey (1992: 136) se ha permitido un juicio compartible a este respecto: "fragmentos dramáticos de escaso interés"; melodramas de baja calidad "pertenecientes probablemente a distinto momento creativo" (íbid.:146). "El contraste de esta obra con el contenido de los diálogos hace suponer que pertenece a una etapa muy anterior a estos" (íbid.: 147).

${ }^{3}$ Salvo excepciones significadas, la literatura científica ha dado prioridad a la biografía de Colombine -vista a menudo como curiosidad y en sus aspectos de 'excepción'-, frente al análisis de su abundante obra, algo muy frecuente en el caso de escritoras. La biografía de referencia y etopeya es, sin duda, la de Núñez Rey (2005). Cf. Simón Palmer (1991: n. 942). Una breve semblanza biográfica reciente por Ena Bordonada (2014) y otra más somera en Biblioteca Nacional de España (2016). Puede consultarse una bibliografía unitaria, asequible, bastante reciente aunque incompleta, elaborada por el Instituto Cervantes (2014). Hay una monografía en forma de tesis doctoral: Alfonso (2016: 625-677), pero pese a la extensión, son meros resúmenes de contenido, y solo de tres de los trece diálogos; incluye selectivamente el "Teatro irrepresentable" (en pp. 654-677 en los mismos términos antológicos). Con motivo del actualísimo 150 aniversario del nacimiento de la escritora la bibliografía secundaria crece en estos momentos, esperemos que aportando algo más que lo puramente celebrativo. Su bibliografía secundaria es, con todo, ya muy importante, pero como dialoguista es prácticamente nula, ya que su experimentación con el género literario 
limitaré a ver el alcance y realidad de esas afirmaciones de la autora y la larga tradición literaria europea con la que enlazan sus trece espléndidos diálogos. Estas piezas no se han analizado todavía como diálogos literarios, y es normal aludir a ellas como especies de variado tipo. Federico Carlos Sainz de Robles consideraba en 1975 La voz de los muertos como obra narrativa ${ }^{4}$. Más comprometido resulta ignorar aún el género en $2016^{5}$.

\section{Las "sombras"}

Carmen de Burgos pone a dialogar a abstracciones (Genio familiar), a mitos literarios (Don Juan Tenorio), a grandes autores o creadores antiguos o modernos (Fidias, Cervantes, Leopardi, Rodin), a personajes históricos (Isabel la Católica, Lucrecia Borgia), a tipos humanos o profesionales representativos (el Guardián del castillo de la Mota, un Periodista, una Cortesana, una Madre de familia, el Cura de un pueblo, una alumna de las Ursulinas, una Enamorada muerta y una Jovencita, un Fusilado y un Ahorcado, una Feminista, un Héroe muerto y un Fraile orante, un Verdugo muerto y un Ministro conservador, un Curioso). Se nos dice de estos personajes que son "sombras" -en una ocasión "espíritu misterioso" (Burgos [1911]: 13) - que dialogan con otro interlocutor unas veces vivo (o al menos no explícitamente difunto, como la tradición exigía) y otras no; en muchos casos la ficción mezcla de buen grado los tiempos, subvirtiendo la cronología e introduciendo un mensaje parcialmente atemporal: los muertos recientes aportan novedades y noticias a los muertos antiguos, que 'viven' en el mundo de la ucronía permanente. El título paradójico da "voz" a los "muertos". Se suma, pues, a la larga tradición de diálogos de muertos que, desde Luciano de Samósata en el s. II, son, por convención,

apenas ha interesado a los estudiosos. Cf. Núñez Rey (2005: 289-294). Solo pueden verse, aparte los asientos ya citados, las entradas especializadas a las que remito (pero ajenas a lo que aquí se trata), que aduce Martín Murillo (2014).

4 Sainz de Robles (1975); "una muestra de que no lo leían” según advierte con razón Núñez (1992: 219, n. 21), de quien lo tomo.

${ }^{5}$ Alfonso (2016: 625) habla "d'un genre hybride intermédiaire entre l'essai et la mise en fiction" y de "dialogues comme mode d'expression", por tanto no como género literario sometido a ciertas normas. los únicos dialogantes que dicen la verdad, lúcidos desengañados porque ya no tienen nada que perder. Son diálogos satíricos, de denuncia, crítica social, costumbrista y moral y, en el caso de Colombine, también con propuesta filosófica subyacente o expresa, esto último no siempre explícito en Luciano, que ríe abiertamente de la vanidad humana.

Las inquietudes principales de los diálogos de Colombine tocan desde el mundo del sentimiento hondos problemas de ética y de espiritualidad: preocupación por el sentido de la muerte, por la filosofía del amor -aplicada a los dos sexos, pero sobre todo al femenino-; en materia metafísica sostienen tesis materialistas (niegan la Providencia, la vida ultraterrena, Dios aparece como fantasía del hombre, insisten en la pequeñez e igualdad del ser humano con argumentos de tradición filosófica materialista y epicúrea, no penitencial y estoica). Aflora en ellos igualmente la inquietud por grandes nociones de aplicación transhistórica conflictiva, como Justicia, Honor y Fama, Derecho, Política, Patriotismo, Religión, donde resulta fecundo el enfrentamiento entre antiguos y modernos. La autora muestra asimismo interés extraordinario por la educación (sobre todo denuncia la que reciben las mujeres y los sectores marginales de la sociedad), lo que no es extraño dado que su profesión es también la de formadora de maestras ${ }^{6}$; o presta atención a la guerra, pues coincide con una fuerte corriente pacifista de escritores que frisan la I Guerra Mundial y usan argumentos análogos contra la barbarie belicista creciente y la violencia destructora e inútil. Los debates son de actualidad, y vivos y muertos pueden comentar sucesos recientes saltando aduanas entre los siglos. Sus interlocutores hablan con desigual "serenidad", y lo más frecuente es que uno entreviste a otro, pero en todo caso suelen estar enfrentados por forma de pensar, o por hábitos morales, o por educación disfrutada, nivel social, edad, profesión, estado civil y hasta tipo de muerte recibida. Las proyecciones de la autora en uno de ellos suelen ser notorias, aunque también puede distribuir la opinión entre los dos hablantes.

${ }^{6}$ De hecho se reivindica desde hace unos años la necesidad de estudiar mejor la faceta educadora y pedagógica de Carmen de Burgos, descolorida bajo el fulgor de su obra periodística y narrativa, la que aparentemente a ella más interesó. Cf. Luis Gómez y Romero Morante (2006).

UNED. REI, 6 (2018), pp. 37-87

ISSN 2340-9029 
Carmen de Burgos pudo, por cronología, leer a Luciano completo en la traducción morigerada de Baráibar ${ }^{7}$, pero quizás solo lo conoció a través de Leopardi. En todo caso conserva la distancia y perspectiva del samosatense para investigar y juzgar las cosas, el uso de observatorios de la humanidad que facilitan la denuncia del antropocentrismo y de la dignidad del hombre como conceptos falsos, negados por la naturaleza efímera y frágil de la condición humana.

Dado que esto implicará abordar aquí de forma rápida materias complejas, adelanto una cuestión previa importante, para evitar incurrir en el "mondolirondismo" que gustaba denunciar Julio Caro Baroja: la 'confesión' de modelos de Carmen de Burgos no ha de entenderse a mi juicio como sistemática, sino como gesto de afinidad referencial, práctica común, por otra parte, en los siglos XIX y parte del XX hasta en los trabajos científicos. Su familiaridad con las fuentes citadas es solo contingente. A cambio, considero que Colombine sí se aproxima de forma imaginativa e independiente, con aliento propio, a los escritos de Leopardi y, en menor medida, del resto de autores citados y de otros que calla. No encontraremos aquí tanto citas textuales o menciones explícitas como imitación intelectual y estéticamente dinámica que riega de forma subyacente y profunda la escritura. Por ello es accidental saber si la influencia es directa (no tiene excesivo interés probarlo) o a través de estímulos mediados. Más que la incorporación de ideas o convenciones previas es importante observar cómo los pensamientos y las formas germinan de manera personal gracias a esa relación con planteamientos y meditaciones anteriores sobre problemas similares $^{8}$. Si esta aproximación comparatista es conveniente porque significa enmendar y enriquecer el tradicional enfoque de la Quellenforschung, se hace en cualquier caso imprescindible cuando se trata de lucianismo, una influencia que atraviesa los siglos en constante y enmarañada transformación a cada presente y sucesivo lector, influyendo sobre sus vidas y acti-

\footnotetext{
${ }^{7}$ Luciano (1889). Conocía, en cualquier caso, al traductor, ya que también incluye la versión española que hizo este del canto XXXIII de Leopardi, «Il trammonto della luna», en su estudio de la vida y la obra de Leopardi, del que se trata más adelante. Además, Federico Baráibar (1878) había traducido también el «Diálogo de Malambruno y Farfarello» de Leopardi.

${ }^{8}$ En términos generales, no referidos a la autora, cf. Martindale (2007: 309).
}

tudes hasta hoy mismo. Este trabajo, por tanto, aborda de forma modesta también la recepción de Luciano y de otros referentes de Colombine, en la idea de que esta participa aún de la vieja querella europea entre "Antiguos" y "Modernos", una disputa antropológica y cultural que nació en la España del siglo XVI (aunque la mayor parte de los estudiosos de la querella lo ignoren ${ }^{9}$ ), y alcanza a muchos intelectuales y escritores europeos hasta los siglos XX y XXI. La discusión entre “Antiguos" y "Modernos” dista de ser un juego banal, pues se plantea lo que la modernidad debe hacer con la historia, la religión, la visión del mundo, la fama, la estética, la herencia, la literatura, la moral, la ciencia de los antiguos y, por tanto, las suyas propias. Leopardi participó en la polémica de forma singularmente interesante con sus Operette morali, y por eso llega a su traductora Colombine, que acomoda de nuevo a su tiempo y situación una determinada forma de ver la antigüedad.

\section{2. "Sócrates, Platón..."}

Si volvemos ahora a los modelos aducidos por Carmen de Burgos hay que convenir que su declaración debe entenderse más como forma de encaminar a sus lectores hacia signos universales de familia literaria que como lecturas realizadas por ella con la suficiente profundidad y sosiego, a excepción del poeta de Recanati. En sus diálogos solo se ven ecos muy lejanos ("un vago recuerdo de verdades enunciadas...") de Sócrates -que no dejó diálogo escrito y solo conocemos por las idealizaciones de varios discípulos- o de Platón. Por ejemplo, bautizar a cada coloquio de forma doble: un nombre abstracto por título (El Amor, El Honor, La Grandeza, La Virtud, El Patriotismo, La Muerte...) seguido de un subtítulo asociado al nombre propio o común ("Diálogo entre..." la Autora y su genio familiar, Isabel la Católica y el Guardián del castillo de la Mota, Fidias y Rodin, etc.), o asociado al ejemplo o caso (una Cortesana y una Madre de familia; un Fusilado y un Ahorcado, etc.). Fue procedimiento general entre

${ }^{9}$ Nace en España con La ingeniosa comparación entre lo antiguo y lo presente de Cristóbal de Villalón (1539).

UNED. REI, 6 (2018), pp. 37-87

ISSN 2340-9029 
los antiguos (no solo Platón) para intitular sus diálogos ${ }^{10}$ y pervivió en las distintas literaturas desde los padres de la Iglesia o el occidente medieval, alcanzando a la edad moderna. Aunque se ha insistido en la evidente relación del genio familiar de Burgos con el de Leopardi ("Dialogo di Torquato Tasso e del suo genio familiare"), no parece que haya que excluir el conocimiento del origen de la señal demónica u "oído del alma" en el Sócrates platónico $^{11}$.

De todos los dialoguistas antiguos, las mayores analogías pueden establecerse con el gran satírico Luciano; pero no se piense en una inspiración directa en sus tan imitados Diálogos de los muertos, sino en la inspiración mediada, es decir, en el lucianismo recreado a través de los siglos $\mathrm{y}$, muy especialmente, durante y después de los Renacimientos europeos, como se verá enseguida. Quizás esa es la razón por la que no menciona el nombre de Luciano, pese al elevado número de veces que algunos de sus paradigmas más admirados lo hacen.

Diferente es, por tanto, el caso de los otros modelos modernos que alega Carmen de Burgos, como Parini y Leopardi -ambos autores de diálogos y conocedores de Luciano; al segundo de ellos le dedicó una nutrida biografía acompañando a una amplísima antología textual- ${ }^{12}$; u otros no alegados, como Renan -también dialoguista ${ }^{13}-$, al que ella tradujo; o Voltaire, al que conocía de referencia. Como escritora prolífica, aparte de estar relacionada con varios autores europeos, frecuenta una tradición de

${ }^{10} \mathrm{O}$ a la inversa, un nombre propio y un subtítulo descriptivo: por ejemplo, Gorgias. Sobre la retórica, de Platón.

${ }^{11}$ Véanse, por ejemplo, las alusiones de Platón en los diálogos más conocidos: Fedro 242b9, Téages 129b8, Apología 31c7-d6 y 40a2-c3, Eutifrón 3b5-6, República 496c35, Teeteto 151a3-5, Alcibíades 1034-6, Eutidemo 272e (y en este último, Platón 1992: 205 , nota 13 ).

${ }^{12}$ Sobre el reconocimiento de la imitación de Leopardi, cf. entre otros Utrera (1998: 207) y sobre todo infra.

${ }^{13}$ No pueden en este caso, por razones de fecha, haber influido específicamente los Dialogues philosophiques de Ernest Renan, escritos en mayo de 1871 pero solo publicados en 1925 (cf. Renan 1925: Préface, 7). De Renan (1823-1892) tradujo Los Evangelios y la segunda generación cristiana (1904) y La Iglesia cristiana (1905): cf. Núñez, 1992: 214 dialoguistas modernos en la que ahora no se puede profundizar y quedará para otro momento, de la que se perciben ecos, a menudo más ideológicos que formales. En el origen de aquella estela se encuentra Fontenelle, al que no menciona, quien quizás inspira, de modo directo o indirecto, algunas técnicas esenciales y algunos rasgos de estructura y formales. Fontenelle es pieza a mi juicio esencial, en cualquier caso, para entender todo el edificio posterior de esta tradición dialogal hasta llegar, mucho después, a $L a$ voz de los muertos.

\section{Intermedio: el giro de Fontenelle y el lucianismo moderno}

Fontenelle representa el primer cambio importante en el lucianismo tras los grandes imitadores renacentistas. Él es el principal responsable del giro que todas las literaturas europeas adoptan hacia un lucianismo de segundo grado, el que se instala hasta Voltaire, Wieland o Leopardi ${ }^{14}$, y que alcanza también, ya en el siglo XX, entre otros textos a La voz de los muertos. Los diálogos de muertos se constituyen en un subgénero de moda desde la segunda mitad del siglo XVII en Francia e Inglaterra y van a dominar por completo el panorama de 1680 a 1780; en Alemania la moda fructifica algo más tarde y dura hasta principios del siglo XIX, pese al desplazamiento literario que se produce en Europa en esos años hacia intereses más metafísicos y emocionales, menos afines al racionalismo y la sátira que arrastran los imitadores de Luciano. Pero no todos los escritores lucianescos satirizan la razón y su discurso. Colombine es, por ejemplo, una buena muestra de singular racionalismo en la Edad de Plata.

El giro novedoso que da e imprime Fontenelle tiene en la base su uso confesado de la traducción muy popular de Luciano, hermosa y poco fiel, hecha por Perrot D’Ablancourt $(1654)^{15}$, con su derivado en Inglaterra,

${ }^{14}$ Robinson (1979: 144-163); Correard 2008 (que he conocido recientemente gracias a la generosidad de su autor) y Correard (2011: especialmente 51-52 y passim). Para el cambio producido en el canon lucianesco y menipeo es indispensable esta última síntesis. Conviene ver también DeJean (1997).

${ }^{15}$ Aparte de los trabajos citados de Robinson y Correard, y los que se alegan en nota 16, conviene reparar (muy selectivamente) en Zuber (1997: 181-188); Bernier (2006: 49-62); Bury (2007: 148-174); Cazanave (2005: 427-442), (2007a: 122-129) y 
conocido como el Dryden Lucian (1711). Luciano deja de ser el escritor ateo, irreverente y desvergonzado que sentenció una parte muy representativa de la Contrarreforma (no toda ella, o al menos no a todo Luciano) y se convierte en pieza esencial para la maduración de conceptos clave del clasicismo francés ("urbanité", "galanterie", "mondanité", "honnêtes gens", etc.); no se recupera el Luciano erudito e híbrido, de fuentes complejas, característico de los humanistas, sino un único texto, los Dialogi mortuorum (Correard 2011: 56). El contenido satírico de los numerosos imitadores de Fontenelle en los siglos XVII (Fénelon sobre todo) y XVIII incluye extremismo religioso o político, temas discutibles de actualidad, mayoritariamente opiniones escépticas desde el punto de vista del conocimiento, la filosofía y la ciencia; en este aspecto el subgénero une a escritores muy distintos como Boileau, William King, Richard Bentley, Fassmann, Thomasius, etc.; la aportación racionalista de Fontenelle en política, religión y diversos saberes alcanza después a otros como Rémond de Saint-Mare, Demachy, Pesselier, Boulenger de Rivery, Vauvenargues, Voltaire o, en Inglaterra, Lillelton, William King o Matthew Prior, y en Alemania al gran Wieland ${ }^{16}$.

Las principales variaciones de forma dialógica, presentes desde Boileau y Fénelon, son sobre todo obra de Fontenelle (1683-1684) ${ }^{17}$; por ejemplo, el recurrir a figuras antiguas y medievales con una puesta en escena lucianesca (como en Vitarum auctio) para destacar el absurdo de sus doctrinas o ideas más características. Pero a la vez la renuncia deliberada al escenario infernal, según explica en su epístola "A Lucien aux Champs

(2007b: 73-84). Correard (2011) matiza muy bien, en lo que a Fontenelle se refiere, sus novedades independientes de la traducción de Perrot D'Ablancourt; afectan a la ironía, el equívoco y la paradoja más directamente originales del escritor sirio que, remozados por el autor francés, crean un nuevo modelo de imitación que liga su forma a la querella de antiguos y modernos y al conflicto antropológico y cultural entre herencia y modernidad. Correard (2011: 58) añade la posibilidad del recuerdo a las Vidas paralelas de Plutarco.

${ }^{16}$ Egilsrud (1934); Robinson (1979: 144-163); Pujol (2005); Correard (2011); Andries (2013).

${ }^{17}$ Fontenelle revisa el texto de Les Nouveaux Dialogues des Morts a la altura de la $3^{\mathrm{a}}$ ed., por la que cito; al año siguiente, 1684, añade la Deuxième partie y el Jugement de Pluton. Cf. Fontenelle $\left(1683^{3}\right)$ y (1684). Traducción española: Fontenelle (2010).
Élisiens", donde anuncia nuevos temas con respecto al modelo, elimina a los dioses y pone solo a hablar a muertos ilustres, con propósito moral:

J'ai suprimé Pluton, Caron, Cerbere et tout ce qui est usé dans les Enfers (Fontenelle, 1683, "Epistre”, f. aiii vto.).

Tous vos Dialogues renferment leur Morale, et j’ay fait moraliser tous mes Morts; autrement ce n'eust pas esté la peine de les faire parler; des Vivans auroient suffy pour dire des choses inutiles. De plus, il y a cela de commode, qu'on peut suposer que les Morts sont gens de grande refléxion, tant à cause de leur expérience, que de leur loisir; et on doit croire pour leur honneur, qu'ils pensent un peu plus qu'on ne fait d'ordinaire pendant la vie. Ils raisonnent mieux que nous d'icy-haut, parce qu'ils les regardent avec plus d'indiférence et plus de tranquillité, et ils veulent bien en raisonner, parce qu'ils y prennent un reste d'intérest (Fontenelle, 1683, "Epistre", ff. a iiii- [a v]).

Probablemente esa serenidad y ponderación que Fontenelle atribuye a los muertos -sin privarlos de naturalidad y libertad, pues su lenguaje ya no tiene límites de expresión- fueron motivo suficiente para que este subgénero cautivara a los escritores de varios siglos. Sus palabras son más razonables que las de los vivos, lo que hará las delicias sobre todo de los autores satíricos.

Estructura su obra en diálogos de muertos antiguos, de muertos antiguos y modernos y de muertos modernos, en doble serie (con seis partes en total y el "Juicio de Plutón" añadido al fin). Presenta situaciones y hechos históricos, religiosos o culturales con el objetivo de ponerlos en cuestión. Temas lucianescos como la hipocresía de los filósofos, el absurdo de los cultos funerarios, la sátira de la galantería, etc. están ya en la adaptación satírica que hace D’Ablancourt a los usos de las clases aristocráticas del siglo XVII francés. Fontenelle explota sobre todo la paradoja como vía de instrucción moral. Sus diálogos ponen en danza a dos personajes antagonistas, generalmente en parejas insólitas que solo coinciden en la ficción, pues proceden de mundos y tiempos distintos; conversan escritores, filósofos, nobles, reinas, cortesanas, astrólogos y conquistadores, gentes de 
diferentes clases sociales, profesiones y lugares alejadas en el tiempo, que queda abolido. La paradoja se traduce a veces en un estilo provocador que escandaliza a uno o a otro. Rara vez, sin embargo, usa a un interlocutor para socavar la opinión del adversario, como hacía Luciano, y como a menudo también hace Colombine; prefiere equilibrarlos, bien estableciendo una polaridad ("Milon et Smindirides", "Socrate et Montaigne", "Charles Quint et Erasme", "Érasistrate et Démétrios", "Paracelse et Molière", etc.) o creando paralelos paradójicos ("Alexandre et Phrynè", "Hélène et Fulvie", "Artémise et R. Lulle", "Lucrèce et Barbara Plomberge", "Hernan Cortès et Moctezuma", "Guillaume de Cabestan et Albert-Fréderic de Brandebourg", etc.). Este modo de contribuir de forma sopesada a la querella de Antiguos y Modernos sin definición final, o con igual consideración del personaje antiguo y del moderno, delata identidad bajo la diferencia, la misma incertidumbre escéptica por ambas partes, y la correlativa negación de la idea de progreso. El recurso a personajes históricos como elemento de verosimilitud aspira a comprender mejor al ser humano, pero desaparecen los tabúes a través de la paradoja, la provocación y el absurdo, se conduce a un nuevo pensamiento que pone en cuestión el difundido por la Historia y se llega a una verdad más humana y profunda. Es decir, la paradoja se torna particularmente importante en materia histórica: el lector sospecha al fin que las apariencias engañan, que la verdadera Historia de la Humanidad no se ha transmitido fielmente y aún no está escrita. La línea entre razón y verdad se vuelve difusa. Los muertos demuestran la inanidad de las últimas grandes cuestiones, de las virtudes falsas o de los prejuicios: la experiencia nunca sirve. También entre los modos efímeros de cada existencia asoman elementos estables o esencias de la naturaleza humana. Ante el espectáculo del mundo, ante la vanidad de las ciencias, no cabe más filosofía que la escéptica, la duda perpetua, comprender la relatividad de todo. El Fontenelle de la madurez y el de los Entretiens sur la pluralité des mondes ya no pensará igual que el joven de los Nouveaux Dialogues des Morts. Abandonará el escepticismo epistemológico por un criterio de verdad ${ }^{18}$.

${ }^{18}$ Pueden verse los trabajos citados de Correard (2008) y (2011): en este último define así la paradoja específica de los Nouveaux Dialogues des Morts: "respect sans déférence inspiré par les «belles infidèles»; rhétorique de l'imitation dans laquelle l'auteur s'efface volontiers devant sa source, mais innovation revendiquée par l'élimi-
La difusión de los diálogos incluyó la forma de littérature de colportage y las antologías; no fue necesariamente diseminación completa ni unitaria, por lo que aparecen distintas ediciones con estructura distinta. Durante los siglos XVIII y XIX fueron muchas las ediciones francesas y se traduce muy pronto al inglés e italiano. Existe una versión completa española que quedó manuscrita, obra del liberal Manuel Lozano Pérez Ramajo (a partir de una ed. de Amsterdam, 1742), traducción que pone recientemente en valor Sáez Rivera (2015). El nacimiento de la prensa periódica parece empezar a comprender la importancia de la formación de la mujer y de la opinión pública femenina; que los traductores, probablemente varones -aunque quizás no todos-, introduzcan diálogos de Fontenelle en la prensa destinada a mujeres es quizás síntoma singular del descontento de un sector importante de la sociedad con el Antiguo Régimen: en torno a las Cortes de Cádiz, con el nacimiento de la libertad de imprenta, varios diálogos de Fontenelle aparecen traducidos entre los años 1804-1807 en el Correo de las Damas, o Poliantea Instructiva, Curiosa y Agradable de Literatura, Ciencias y Artes (Cádiz) ${ }^{19}$.

Pero no se trata de justificar cómo pudieron llegar los Nouveaux Dialogues des Morts a Colombine, que aparte de leer y escribir para la misma prensa femenina que difundía a Fontenelle, leía y traducía francés ${ }^{20}$.

nation de la mythologie, par l'intérêt pour l'histoire envisagée de manière critique, par la présence des femmes et de la culture mondaine; refus de la pédanterie qui permet de retrouver la fraîcheur du spoudogeloion antique et l' "atticisme » de Lucien; confrontation d'une mémoire historique et des «nouvelles» fournies par une actualité immédiate ou récente; équilibre entre la citation érudite, intégrée en toute discrétion dans le propos, et l'impression de désinvolture permise par l'oralité du dialogue." Correard, 2011: 57).

${ }_{19}$ Noticia que debo a María Jesús Fraga. Cf. también Fraga, 2016: 283 y passim. Es, pues, muy mejorable la información sobre traducciones que aporta la última versión española de los Nouveaux dialogues...: Fontenelle (2010: en especial 31-32).

${ }^{20}$ Era, según Núñez (1992: 214), la única lengua que aparentemente traducía de forma directa, "de modo que en algunos casos ella se basaría en otras traducciones previas". Cf. ahora para su dedicación traductora general, Simón Palmer (2016: 41-59); según $\mathrm{M}^{\mathrm{a}}$. C. Simón, Burgos tradujo directamente desde francés e italiano. En todo caso sí está documentada su condición de alumna de italiano en la Escuela de Idiomas de Jesús Maestro, información que debo y agradezco a Carmen Marchante.

UNED. REI, 6 (2018), pp. 37-87

ISSN 2340-9029 
Se trataba de entender por qué la influencia de Luciano es en sus diálogos (como en los de Voltaire, Parini y Leopardi), de segundo grado, y por qué se ha producido un desplazamiento novedoso.

Carmen de Burgos no coincide con la dispositio de Fontenelle (muertos antiguos; muertos antiguos en diálogo con modernos; muertos modernos), y da protagonismo a los muertos modernos; los muertos antiguos como dialogantes exclusivos desaparecen y solo coinciden en la fórmula intermedia, antiguos con modernos, siguiendo el mismo esquema retórico de la syncrisis lucianesca: "Diálogo ente Isabel y el Guardián del castillo de la Mota"; "Diálogo entre Judas y el Cura de un pueblo"; "Diálogo entre Cervantes y un Periodista"; "Diálogo entre Fidias y Rodin"; "Diálogo entre Lucrecia de Borgia y una Educanda de las Ursulinas"; incluyo también en este grupo el "Diálogo entre don Juan Tenorio y una Feminista", donde hay que considerar al Tenorio como 'antiguo', aunque remita al burlador de la obra de Zorrilla $(1844)^{21}$. El paralelo suele traer la parodia y la sátira, por lo general aquí con potencial subversivo de los valores sostenidos por la cultura oficial de la España del primer reinado de Alfonso XIII.

Incluso si el tema debatido es el mismo, o análogo, el tratamiento es también muy distinto. Por ejemplo, "Safo y Laura" de Fontenelle discute un asunto paralelo al de "El Amor. Diálogo entre una Enamorada muerta y una Jovencita”, pero diverge el planteamiento. Y es que los dialogantes de Fontenelle comentan con calma problemas comunes o generales pero no se oponen de modo más o menos enfurecido y apasionado como los de Colombine: el escepticismo de Fontenelle se sustituye por una perspectiva subjetiva de protesta ética, social y civil, porque la autora tiene más interés en presentar tipos concretos responsables de prejuicios censurables, incluso aunque todos los personajes tengan su "razón" y hasta su "capricho" 22

${ }^{21}$ No incluyo, en cambio, en esta fórmula el "Diálogo entre Leopardi y un Curioso", donde el escritor filósofo aparece como moderno.

${ }^{22}$ Como dice en el "Diálogo entre la Autora y su Genio familiar": "No he querido más que repetir todas las voces de las humanas creencias, las más opuestas entre sí, haciendo igualmente respetable toda razón y todo capricho, y como no creo que para hablar de cosas que llaman trascendentales haya que ponerse hosco, pretendí darles una amable forma literaria." (Burgos [1911]: 11). para ser comprendidos. En ese aspecto enlaza más con el lucianismo quinientista, previo a las modificaciones del recreado en el Grand Siècle, y con el ilustrado, en particular desde Voltaire.

Aunque su participación en la querella de Antiguos y Modernos es ya, como es lógico, mucho más comedida que la de Fontenelle, Burgos rechaza en sus pares antitéticos, como él, la identificación de la decadencia con lo antiguo y del progreso con lo reciente -y por tanto siempre con el interlocutor moderno-; no necesariamente concede, pues, méritos especiales en función de la distancia histórica; su mirada es la moralista distante sobre las transformaciones históricas para denunciar siempre el prejuicio, el teatro de las apariencias y la sinrazón, haciéndolo con la libertad de palabra y la parresía lucianescas. Sirven como ejemplos los siguientes: "Diálogo entre Judas y el Cura de un pueblo", "Diálogo entre Cervantes y un Periodista" o "Diálogo entre Lucrecia de Borgia y una Educanda de las Ursulinas”. El personaje de Cervantes, en crítica a la Academia de la Lengua, se queja de que los eruditos posteriores le han atribuido cosas que nunca pensó (Burgos, [1911]: 97-98), como hacía Fontenelle en "Platon et Marguerite d'Écosse”, donde el filósofo denunciaba la forma que tenía la posteridad de interpretar sus escritos ${ }^{23}$. Colombine enfrenta aquí tiempos antiguos y modernos en formas de escribir, de concebir la gloria o el poder, o el honor, o el estudio, o el arte. Cervantes se presenta anacrónicamente como materialista (íbid.: 103) y su escepticismo gana frente a un periodista que solo aspira, guiado por el oportunismo, a causar sensación con su entrevista en el periódico (íbid.: 101-102). A veces la fórmula literaria elegida es la entrevista: en "El arte. Diálogo entre Fidias y Rodín”, Fidias patrocina el racionalismo griego (íbid.: 107), desdeña la risa y defiende sufrimiento y dolor como pasiones más refinadas, en puro anacronismo leopardiano; Rodin es quien lo 'entrevista'.

Eso no evita que a veces sea el moderno el que lleve la razón, porque los universos de vivos y muertos se confunden y la ironía autorial recurre al mundo al revés; así ocurre en "Diálogo entre don Juan Tenorio y

\footnotetext{
${ }^{23}$ Después lo repite Leopardi, en este caso como en otros seguramente la fuente más directa de Carmen de Burgos.
}

UNED. REI, 6 (2018), pp. 37-87

ISSN 2340-9029 
una Feminista" o en "Diálogo entre Leopardi y un Curioso". Precisamente en el interrogatorio del Curioso a Leopardi se repite este hallazgo de la exégesis sesgada. El poeta filósofo cuestiona de nuevo la interpretación de los escritos a través del tiempo, lectura que no busca la gloria del escritor sino la del intérprete (íbid.: 124-125), y se siente particularmente defraudado de sus comentaristas y exégetas (íbid.: 125-126). Cuando el moderno lleva la razón, normalmente Colombine está criticando unos valores anticuados y proponiendo una alternativa nueva, dictada por la naturalidad y la autenticidad. Hay prejuicios, valores e ideas que nunca deberían abandonar el sepulcro.

Pero tampoco gana la partida necesariamente el vivo ni el moderno; a menudo es todo lo contrario. Además los tiempos se confunden e importa la clarividencia de los muertos, que han alcanzado la omnisciencia desde su lucidez desencantada. Los mejores ejemplos, todos de diálogos entre modernos que enfrentan sistemas morales e ideológicos antagónicos, son: "Diálogo entre una Cortesana difunta y una Madre de familia", "Diálogo entre un Héroe muerto y un Fraile orante" y "Diálogo entre un Verdugo muerto y un Ministro conservador"; también -pero son dos muertos- el "Diálogo entre un Fusilado y un Ahorcado". En cualquier caso, el sistema no es absoluto. El punto de vista autorial a veces se proyecta en el vivo o el moderno (la feminista frente a Juan Tenorio) y otras en el muerto (el verdugo frente al ministro conservador, Cervantes frente al periodista, Lucrecia Borgia frente a la educanda de las Ursulinas, Leopardi frente al curioso); pero otras lo hace en los dos para enfrentar dos formas de arte (Fidias y Rodin), o se distribuye entre los dos dialogantes al menos en un número suficiente de argumentos: "Diálogo entre una Enamorada muerta y una Jovencita”, "Diálogo entre Isabel la Católica y el Guardián del castillo de la Mota", "Diálogo entre un Fusilado y un Ahorcado". Esto último no es lo más frecuente. La pluralidad de confrontaciones trae siempre de suyo el contraste entre numerosos valores de muy diverso signo.

Frente al escepticismo del Fontenelle joven, Colombine, más racionalista, sí distingue, muy en especial en el terreno moral, entre verdadero y falso, aunque ese criterio ético de verdad, en sí mismo relativo, pueda administrarse indistintamente a un antiguo o a un moderno (a diferencia también del lucianismo de Fénelon que, pese a la influencia de Fontenelle, daba la victoria a los modernos). A veces la moralización con los ejemplos comporta escándalo, como en Fontenelle, porque son los réprobos los que tienen razón, voz satírica eficaz para demostrar la vanidad de las grandes cuestiones: Lealtad, Patriotismo, Heroísmo, Amor, Gloria (o Fama), etc., igual de inanes para todos, y de modo especialmente lacerante para los muertos. Los grandes conceptos, los que se suelen escribir con mayúscula reverencial, son relativos, o al menos cambian de significado en el transcurso del tiempo:

Hay verdades que se deben decir y conceptos abstractos que se necesita fijar: Honor, Gloria, Amor, Inmortalidad, Virtud, Patria... ¿ No cambian de significado las palabras en el vocabulario? Pues si esto sucede y la palabra no es más que el signo de la idea, es indudable que las ideas han cambiado y que se necesita examinar lo que significan ya entre nosotros. (Burgos [1911]: 11) ${ }^{24}$.

Existe para Colombine la responsabilidad de reformular esos grandes conceptos. Lo dice de maneras distintas, siempre con desenfado:

No pretendo hacer sistema ni me importa nada lo que puedan demostrarme. Mis arbitrariedades valen tanto como las deducciones lógicas más severas, puesto que cada sabio viene a desmentir el trabajo de los anteriores (Burgos [1911]: 11)

Personajes históricos sirven para examinar críticamente la historia de España y para traerla al presente: en "La grandeza. Diálogo ente Isabel y el Guardián del castillo de la Mota”, el espacio es la fortaleza donde la 'sombra' de Isabel espanta los conejos al guardián que está cazando (íbid.: 55); el castillo, con un presente en ruinas pero convertido en atracción turística, es el mismo donde para Isabel está, o ha estado, encerrada su hija $\mathrm{D}^{\mathrm{a}}$ Juana a la que el guardián ha oído suspirar en la torre del homenaje (íbid.: 55). Se discute sobre el progreso en lo material (la reina vivía peor que cualquier mujer acomodada de "ahora", p. 56), pero Isabel acepta ante el Guardián saber más ahora: "que de saber yo entonces lo que me han enseñado la

${ }^{24}$ Probablemente es eco leopardiano, como luego se verá. 
muerte y los siglos, muchas cosas no hiciera" (íbid.: 56). Arrepentida del descubrimiento y colonización de América, de la intolerancia, de su viudez (Fernando ya no es su marido, sino de Germana de Foix), reconoce estar unida a su antiguo esposo por "amor de reyes" (íbid.: 57). "En la tumba he visto la vida universal" (íbid.: 59), dice, lo que la ha hecho más sabia y reflexiva. Carmen de Burgos puede dejar traslucir la idea de todo el universo como una explosión de vida en medio de la muerte y la nada, y la convicción lucianesca y leopardiana de que el ser humano no es el único ni el centro (íbid.: 60). Se igualan socialmente la reina y el pesero y también se trufan otros ecos leopardianos: "bien vale un buen sueño más que una mala realidad. La ilusión lo es todo” dice el Guardián (íbid.: 61).

Los muertos de Colombine han reflexionado, por tanto; son fuente de enseñanza porque han sido buenos aprendices en la experiencia de ese tránsito. Se abre camino así una visión crítica de la historia, no solo de la mano de personajes históricos como la reina Isabel. El Verdugo también ha comprendido la Justicia igualitaria, frente a la imperante, realmente en la tumba: "la he encontrado detrás de la tumba" (íbid.: 90).

Más que descifrar el mundo, parece necesario, en general, interpretar al ser humano que se revela en la historia a través de la política, la vida social, el poder o el amor, su ética o sus prejuicios, con una razón ineficaz pero deseoso de lograr lucidez en la discusión. La lengua en $\mathrm{La}$ voz de los muertos se llena de la naturalidad y sentimiento fuerte de los interlocutores, lo que da esencialidad a los temas. Entretanto, sin necesidad de epojé, el lector comprenderá la relatividad de todo y ejercerá el adiestramiento inteligente de la duda, a menudo a través del humor.

En el último diálogo, la duda se multiplica. El Curioso interroga a Leopardi y este aparece como un muerto menos afín a los del subgénero: no está, como los demás, contento ni tranquilo, porque a los muertos acompañan sus recuerdos. Leopardi tampoco es un difunto distante como los de Fontenelle, o como algunos de Carmen de Burgos, sino implicado, prendido de las tristezas de la vida, descontento de estar en su tumba (íbid.: 126); aún experimenta con los sentidos y sueña (íbid.: 127), se queja de la filosofía aunque reconoce su función consolatoria en vida (íbid.: 127). La autora parece poner en cuestión sus propias tesis, como a menudo hace
Luciano. Colombine acomoda en Leopardi-personaje pensamientos de Leopardi-escritor (más se duele el más educado y sensible, el tedio vital, etc.). El sufrimiento solo cesa con el cambio de forma (íbid.: 130) y no está garantizado que no se prolongue si nos prolongamos en otros seres del universo (íbid.: 130), punto en el que vuelve a la idea de su diálogo "Preliminar". Leopardi-interlocutor lamenta haber perdido el tiempo en estudios porque tras la muerte ha sabido que eran mentira (íbid.: 130); es otro muerto que aprende. Al final de sus reflexiones quizás se mezclan efectos especiales del Dialogo sopra la nobiltà de Parini: el personaje Leopardi pierde la conciencia cuando los gusanos devoran su cerebro (íbid.: 132), en recuerdo de la degradación progresiva del Noble al final de la conversación del Dialogo sopra la nobiltà, tema sobre el que volveremos.

\section{Voltaire, ¿un presentimiento?}

En su enumeración de referentes, Carmen de Burgos no cita a Voltaire (1694-1778), pero lo conoce al menos superficialmente y lo menciona muchas veces en su versión de las Operette. Pudo frecuentar varias obras suyas (sobre todo narrativas y teatrales) difundidas en España y desde luego, con más facilidad, el Voltaire "de bolsillo" del Diccionario filosófico [1764] que la editorial valenciana Prometeo publicó sin nombre de traductor ni autor (s. a., pero 1901) por los mismos años en que editó ella sus propias obras ${ }^{25}$. Era obra apta para elevar la formación cultural, ética y política de los ciudadanos que las corrientes liberales educadoras de la opinión pública pusieron en circulación por toda Europa en varias lenguas. La $1^{\text {a }}$ edición francesa del Dictionnaire philosophique portatif aparece anónima en 1764, sin nombre de impresor y con lugar de impresión falso (Londres en lugar de Ginebra, donde probablemente lo imprimió Grasset); cundió rápidamente la atribución a Voltaire y tampoco se hicieron esperar las prohibiciones del Parlamento de París y del Índice romano (1765). Pero el anatema gubernativo e inquisitorial pareció convertirse en recurso publi-

${ }^{25}$ Voltaire ([s.a., pero 1901]). En 1920 (Valencia, Prometeo) la edición, ya ampliada, alcanzó seis volúmenes. Otras ediciones españolas posteriores: Voltaire (1935) y Voltaire (2010; introd. en pp. i-xcviii). Cf. como trabajo de conjunto Trapnell (1972).

UNED. REI, 6 (2018), pp. 37-87

ISSN 2340-9029 
citario, y Voltaire amplió el volumen en varias ediciones de años sucesivos, tanto que el texto dejó de ser "portatif" tras las dos primeras ediciones.

No es fácil asegurar la difusión española de los diálogos de Voltaire ${ }^{26}$, muchos publicados anónimamente y prohibidos desde 1762 por diversos edictos inquisitoriales que alegaban impiedad (Lafarga, 1982: 2830). Él mismo tuvo que protegerse en vida refugiándose en el pseudónimo, el anonimato o publicando en el extranjero, en especial en los Países Bajos. Se conocieron mejor en España, siempre en periodos marcados, el Candide, las Lettres philosophiques, el Traité de la tolérance, el Micromégas, Essai sur les moeurs et l'esprit des nations, etc. que se tradujeron varias veces ${ }^{27}$. Los diálogos escaparon en varios casos a las ediciones de Euvres complètes y algunos circularon como opúsculos fuera de sus compilaciones unitarias $^{28}$. Voltaire combatió de forma incansable el absolutismo, la moral y costumbres hostiles a asentar los principios de una sociedad moderna. Su escritura erudita y su agudeza llena de humor le hacen sobrevivir a las modas durante tres siglos, pese a la persecución sostenida en diversos periodos. Las versiones españolas son muy irregulares pero comienzan en el siglo XVIII" ${ }^{29}$.

${ }^{26}$ Carmen de Burgos pudo leer cómodamente en el Diccionario filosófico, por ejemplo, s.v. materia, el divertido "Diálogo entre un energúmeno y un filósofo" (Voltaire [s.a., pero 1901]: 151-152).

${ }^{27}$ Para el contraste entre la recepción española de la obra narrativa y la filosófica, cf. Lafarga (1982: 216). En el siglo XVIII (desde 1734) hay traducción de Leonardo de Uría y Orueta de la Historia de Carlos XII, rey de Suecia (Voltaire, 1781). La vigilancia censoria se extendió todo lo largo del siglo XIX en España y América, indicio más que probable de su difusión clandestina.

${ }^{28}$ El volumen principal que he manejado de sus Dialogues et entretiens philosophiques es: Voltaire (1786: vol. XXXVI de las O. C.). Otra ed., que añade otros opúsculos: Voltaire (1818).

${ }^{29}$ Los "Diálogos del A.B.C." (c. 1791) son traducción anónima (probablemente de Toribio Núnez, discípulo del ilustrado salmantino Ramón de Salas) de trece de los diecisiete diálogos que Voltaire publicó también anónimamente en 1762: L'A.B.C, dialogue curieux, traduit de l'anglais, de M. Huet (Rodríguez Domínguez 1979: 151 y, en general, 151-155). La traducción española más reciente que conozco solo reúne una pequeña selección (Voltaire, 2015): recoge siete diálogos breves publicados por La Pléïade como miscelánea y aporta una minúscula introducción. También hay versión española del más extenso Diálogo de Evémero (Voltaire, 1996).
Para Voltaire, Fontenelle fue admirable en el tiempo de Luis XIV y apreció mucho sus diálogos (Fontenelle, 2010: 23). Aún así él prefirió otra fórmula: los diálogos volterianos, con muy pocas salvedades, no son de muertos ni, como los de Fontenelle, tienen escenario inframundanal (una excepción relativa serían los Campos Elíseos de "De Lucien, Érasme et Rabelais", donde Luciano sirve para interrogar a los otros dos sobre los males de su época, sobre fanatismo religioso, monjes, cardenales, papa, todo ello susceptible de aplicarse a su propio tiempo). No le interesan los temas tradicionales de igualdad de los muertos; tampoco los juegos lingüísticos de ingenio y las paradojas de Fontenelle. Le importa más el contraste, la ironía y el ataque a la sinrazón. Sus Dialogues son buena muestra de la evolución de los coloquios de muertos en el siglo XVIII (Henrichot, 2005: 153-162). Practica en ellos la enunciación directa e indirecta, y a veces una voz pontifica detenidamente en largos parlamentos (un filósofo, un ministro...). Son obras de polémica y de reivindicación del pensamiento propio; representan al Voltaire más coloquial y directo, pero igual de combativo y revulsivo, algo que sí puede considerarse heredado por Colombine. Es socarrón, por ejemplo, al presentar un cura cerril e inculto frente a un enciclopedista - plenamente adversarios-, y un cura y un ministro protestante -con un enemigo en común, la Enciclopedia, por lo que pueden llegar a entenderse en algo- en las dos partes de sus diálogos "Entre un prêtre et un encyclopédiste" y "Entre un prêtre et un ministre protestant". Los "Dialogues d'Evhémere" (Voltaire, 1786: 441-534), en un total de doce, son una reflexión lúcida y sarcástica entre dos interlocutores, Evémero y Calicatres, sobre el sentido de la existencia, con un examen general de las principales nociones de teología, filosofía, ciencia, moral, etc. desde Grecia, a través de los "bárbaros", hasta el siglo XVIII; se presenta el texto como única obra conservada de Evémero (íbid.: 441).

Voltaire es antirroussoniano leve en 'D’un sauvage et d'un bachelier", personajes opuestos en criterios sobre la vida en sociedad. Aparece como precursor de la defensa de los derechos de los animales en "Du chapon et de la poularde" (íbid.: 95-101), donde compara el trato animal y hábitos alimenticios entre culturas sin escatimar anticlericalismo y denuncia de los hombres que se queman por ideas. Se muestra escéptico en 
cuanto a la necesidad de la causalidad y encadenamiento de las cosas en el "D’un brachmane et un jésuite", y como deísta, que acepta la existencia de Dios por la vía de la razón y la experiencia personal, no de la revelación, en su "Sofronisme et Adelos", o en "De Marc-Aurèle et d'un recollet" (de 1761), con la carta a Federico de Prusia que lo acompaña, una disculpa para mostrar su filosofía deísta, y donde la querella del antiguo (Marco Aurelio) y el moderno (recoleto) presenta la incomprensión entre mundos, no la victoria de uno de ellos. Igualmente en "Les anciens et les modernes ou la toilette de Madame Pompadour” (íbid.: 86 ss.) quedan en armonía las edades. Su aversión a cristianismo y judaísmo como construcciones fanáticas e intolerantes se manifiesta, entre otros, en "D'un caloyer et d'un homme de bien", de 1764 (íbid.: 143-167), donde además de una denuncia de sectas y religiones, el meticuloso hombre de bien -y deísta- se extiende puntillosamente sobre contradicciones de los Testamentos -textos que Voltaire domina- ante las preguntas del calógero; también en "Du douteur et de l'adorateur", donde un incrédulo y un creyente exponen incompatibilidades y paradojas de la religión de Jesús de Galilea, declarándose al final el creyente "de la réligion de tous les hommes" (íbid.: 176). Se protege así el autor de que lo consideren ateo o materialista racionalista (como D’Holbach, La Mettrie o Diderot), aunque no siempre con éxito.

Esos muertos de Voltaire, a veces tan lúcidos como chuscos, simpatizan con algunos personajes de La voz de los muertos y muchos de los conflictos debatidos. No se encuentra en la colección de Colombine ningún préstamo directo seguro, pero la sombra ideológica de Voltaire es palpable en el tratamiento de la mayor parte de problemas de tipo moral y en algunos de contenido social. El derecho puede cuestionarse y contextualizarse porque la muerte siempre trae enseñanza. En "La justicia. Diálogo entre un Verdugo muerto y un Ministro conservador" la justicia igualitaria que el Verdugo defiende y ha comprendido realmente en la tumba (Burgos [1911]: 90) se sitúa dentro de una utopía social universal (el "reino de la Justicia") que trae ecos de Voltaire. En "Sophronisme et Adelos" (Voltaire, 1786: 200-212), Voltaire dice por persona interpuesta:

Si le crime est ainsi puni, la vertu est récompensée, non par des champs elysées où le corps se promène insipidement quand il n'est plus; mais pendant sa vie, par le sentiment intérieur d’avoir fait son devoir, par la paix du coeur, par l'applaudissement des peuples, l'amitié des gens de bien (Voltaire, 1786: 210).

En "Un plaideur et un avocat", el litigante dice, con desacuerdo del abogado: "Ceux qui pèchent uniquement contre Dieu doivent être punis dans l'autre monde; ceux qui pèchent contre les hommes doivent être châtiés dans celui-ci" (Voltaire, 1786: 15). "L'Éducation des filles", un diálogo entre Melinde y Sophronie sobre la educación femenina (Voltaire, 1786: 83-85) permite ver en Sophronie a la antítesis de la educanda ursulina de Colombine, por su crítica despiadada de la formación de las mujeres en los conventos (íbid: 84-85).

El desparpajo con el que Carmen de Burgos toca algunas verdades de la Iglesia e incluso algunos dogmas, enlaza no solo con Voltaire o Leopardi sino con las tradiciones reformistas hispánicas: por ejemplo, se relativizan la traición, la calumnia y la lealtad cuando Judas reclama un altar de apóstol, ante la consternación del Cura, y presenta su traición a Jesús como un instrumento de la voluntad divina en beneficio del género humano, traición que compara con la negación de Pedro, hecho en cambio por la iglesia sumo pontífice. El Cura, ejemplo de hipocresía religiosa y de argumentación apodíctica, quiere hacer negocio eclesiástico con los huesos de Judas (Burgos [1911]: 67-68), una censura cómica de las reliquias, a veces casi textual, del tipo de la renacentista de Alfonso de Valdés ${ }^{30}$. Al final, ambos personajes se enfrentan por una posición distinta ante la traición humana y la fe, pero de camino Judas desmiente dogmas como cielo, infierno y limbo, hace afirmaciones blasfemas sobre la crucifixión y trata con irreverencia a las figuras sagradas, cuya santidad cuestiona.

${ }^{30}$ Carmen de Burgos no pudo en este caso servirse de la 1a edición del Diálogo de las cosas ocurridas en Roma de Alfonso de Valdés por José F. Montesinos (1928), pero tenían ya décadas de fama dos libros de Rodríguez Villa (1875) y (1885), que contenían fragmentos valdesianos, impresos al término del sexenio revolucionario; ambos libros circularon mucho por su capacidad para generar polémica en torno al suceso más inquietante del Antiguo Régimen: el asalto de las tropas imperiales a la ciudad de Roma en 1527. Para su significado y difusión, sobre todo del primero de ellos, cf. Vian Herrero (2011: xiii-lx). También Fermín Caballero (1875) había difundido ampliamente a los hermanos Valdés por las mismas fechas.

UNED. REI, 6 (2018), pp. 37-87

ISSN 2340-9029 
En definitiva, no es aventurado concluir que Colombine heredó el gusto volteriano por la responsabilidad social, la educación de la opinión pública, la función civilizadora del escritor, la causticidad, el revulsivo, la coloquialidad y el sarcasmo de su espíritu crítico, su fruición por la irreverencia y el deseo de agitar las conciencias.

\section{La mención de Parini}

Cuando Carmen de Burgos nombra a Giuseppe Parini (17291799) piensa quizás en su Dialogo sopra la nobiltà de 1757 (Parini, 1961), un diálogo de muertos: en la misma tumba de ocasión conversa un noble fatuo, que presume de apellidos y linaje, con un poeta pobre que le recuerda con sorna macabra, sátira y resentimiento social la antigüedad del linaje de Adán, la igualdad de los hombres y, no digamos, la de los muertos, junto a la importancia de la vida de virtud, en la mejor tradición moralista milenaria. Si los muertos de este subgénero dialogal tienen siempre algo de grotesco en su soberbia, al querer conservar su estatus frente a otros que consideran inferiores, este noble de Parini lleva la palma de petulancia. El poeta recuerda que habla desde la verdad ultramundana ("Questaria malinconica, che qui si respira fino a tanto che reggono i polmoni, non è altro che verità, e le parole, chescono di bocca, il sono pure" (Parini, 1961: [3]); "quest’aria veritiera di questo luogo ov'ora insieme abitiamo", íbid.: [4]). Al final, en cambio, el noble ha dejado de considerar insolente a su interlocutor, ha perdido sus primeras certezas ("Tu m'hai così confuso, ch'io non so dove io mabbia il capo. Io son rimasto oggimai come la cornacchia d'Esopo, senza pure una piuma dintorno", íbid.: [12]) y lamenta no haber conocido antes al poeta para liberarse de algunos prejuicios ("Deh, amico, perché non ti conobbi io meglio, quand'io era colassù tra' vivi; ché io non avrei aspettato a riconoscermi così tardi", íbid.: [15]); el poeta lo ha convencido de que no estuvo rodeado de respeto, sino de adulación, pero también de que su estado de difunto le permite, por fin, conocer la verdad. Si el poeta resucitara, lo último que desearía, por su parte, es ser noble.

Más allá de cierto énfasis escatológico, no son ideas muy originales, ya que están mayoritariamente en el mismo Luciano y en muchos de sus seguidores occidentales desde los siglos XV y XVI en adelante; pero para lo que aquí nos interesa, Parini, aparte su vigorosa influencia neoclásica en las formas, se vincula con varios ideales de la Ilustración (solidaridad social e igualdad de los hombres, denuncia de la nobleza decadente, de la hipocresía religiosa, condena de la guerra, aprecio por los descubrimientos científicos), presentes también en los diálogos de Carmen de Burgos, aunque tampoco pueda defenderse un préstamo textual. Parini no aceptó otros fundamentos de algunos ilustrados (materialismo, libertinismo, ateísmo, crítica eclesiástica, burguesía como clase llamada a sustituir a la nobleza, anticlasicismo, etc.), varios de los cuales sí transparecen en los diálogos de Colombine. Sin embargo, las tesis de las Luces sirven, por vía de Parini, como bando de algunos ideales de la Revolución Francesa en Italia, y como ensayo divulgador de opiniones de Voltaire, Montesquieu, Condillac y los enciclopedistas, en un intento de aportar a la conciencia social italiana nuevas inspiraciones morales y políticas.

En España, desde fines del siglo XIX algunos eruditos se esforzaban en difundir obras de Parini ${ }^{31}$. Es posible que Carmen de Burgos no haya leído directamente su diálogo, sino que su idea vaga se construya a través de Leopardi; este en "Il Parini, ovvero Della Gloria", uno de sus textos en prosa que Colombine tradujo ("Parini o el elogio de la gloria"), pone en boca del escritor lombardo consejos a un joven discípulo sobre la dificultad y sinsabores de conseguir la gloria en las letras o en la filosofía $^{32}$. Al menos Carmen de Burgos se sirve de algunas afirmaciones

${ }^{31}$ En carta de 10 de mayo de 1885 al italianista mallorquín Juan Luis Estelrich (18561923), Menéndez Pelayo celebra la traducción de un texto de Parini: "Aplaudo mucho tu intención de traducir íntegro Il Giorno de Parini. Yo tengo una rarísima traducción castellana del siglo pasado (en verso suelto), hecha por un jesuita español de los desterrados, amigo de Parini; pero no me satisface, porque es floja y tiene demasiados italianismos. Creo que debes preferir por ahora la traducción de Il Giorno a la del tratado de Alfieri [...], que por ser obra poética y casi desconocida en castellano, debe llevar la preferencia, mucho más cuando hay tiempo para todo" (Bertini, 1951: 51). ${ }^{32}$ Es la obra más extensa de las Operette morali, compuesta en 1824 y dividida en doce capítulos. Para la traducción, por la que cito, de Carmen de Burgos, cf. Leopardi-Burgos (s.a. [1911?]: II, 189-217). Pocos años después de publicarse La voz de los muertos, Roberto F. Giusti traduce al español este texto de forma exenta: Leopardi (1917); con- 
para su "Diálogo entre Cervantes y un Periodista": los obstáculos, envidias y maledicencias "hacen que más de un escritor, no solo en vida, sino también después de muerto, esté defraudado del todo en el honor que se le debe" (Burgos [1911]: 191). En el capítulo 3 de "Il Parini...", Leopardi sostiene que para valorar una obra es sobre todo estimable la primera impresión; pero el juicio cambia y la coyuntura para leer ha de ser propicia. Esa incertidumbre del juicio se altera "en diversas edades de la vida, en diversos casos y hasta en diversas horas de un día” (LeopardiBurgos [s.a. 1911?]: 197). El capítulo 8 desarrolla la idea de que la gloria no llega con la vida o con la inmediata muerte. Solo con la sucesión de generaciones y esfuerzos individuales puede valorarse la aportación del genio pensador, nunca entendido por los contemporáneos (como ocurrió a Descartes o a Newton):

... no pienses en recoger en toda tu vida por este descubrimiento alguna alabanza no vulgar. Así no te será alabado, ni aun por los sabios (exceptuando quizás una mínima parte), hasta que repetida la misma verdad, ya por uno, ya por otro, y poco a poco con mucho transcurso de tiempo, los hombres se acostumbren primero por los oídos y luego por el intelecto (Leopardi-Burgos [s.a. 1911?]: 207).

En definitiva, la influencia de Parini es, probablemente, la más difusa de todas las que aquí se señalan.

\section{Y por fin, Leopardi}

Las Operette morali de Giacomo Leopardi (1798-1837) ${ }^{33}$ fueron fuente segura de los diálogos de Colombine. Lo había descubierto en su primera estancia napolitana de 1906 y enseguida lo reivindica estéticamente como poeta-filósofo y como dialoguista ${ }^{34}$. Se debe a Carmen de Burgos

vendría ver en qué medida es o no deudor de la versión previa de Carmen de Burgos. ${ }^{33}$ Leopardi (1982), y en antología: Leopardi (1959). Entre una bibliografía secundaria muy abundante destaco solo: Vitale (1992); Ferraro (1996); Del Gatto (2001) y Colombo (dir.) (2002).

${ }^{34}$ En Burgos (s.a., [1911?]), el vol. I narra la vida de Leopardi entremezclada con sus una de las primeras divulgaciones (no eruditas) de Leopardi en España ${ }^{35}$, al menos en los años subsiguientes ${ }^{36}$, y al menos la del Leopardi dialoguis-

obras y con poemas traducidos por diversos autores; el vol. II recoge obra en prosa, principalmente diecisiete diálogos (pp. 11-108) y algunos pensieri, que influyeron sobre ella: cf. Núñez, 1992: 200-202; también para el riguroso encargo o recopilación de las traducciones de los poemas de Leopardi (Núñez, 1992: 216.) Cf. igualmente Burgos (julio 1909). Núñez (1992: 135-146, 219, 435, 563) atribuye a influencia de Leopardi el descubrimiento que Carmen de Burgos hace de los diálogos. La fascinación e influencia existen, desde luego, y además ella misma las confiesa, pero la factura de sus diálogos propios es más abigarrada y compleja, como aquí se intenta analizar. Resulta sintomático de la ignorancia y descuido en los que ha caído el volumen de Colombine sobre Leopardi el que Giovanni Ferretti no lo mencione entre las traducciones en su art. de la Enziclopedia Italiana. Cf. también Muñiz, 2003: 136-137.

${ }^{35}$ Menéndez Pelayo, que aparece como traductor en la antología de Carmen de Burgos, conocía a Leopardi desde antes de los años 80 del siglo XIX e impulsaba su recuperación entre eruditos: en la citada correspondencia de 1884 a 1886 (Bertini, 1951), Don Marcelino aparece como bien documentado en la literatura italiana y aconseja a Juan Luis Estelrich sobre la inclusión y traducción de textos para una antología de poesía italiana que este prepara y publica poco después (Estelrich 1889): “... me ha parecido exquisita tu versión del Sabato de Leopardi" (carta de 10 de mayo de 1885, en Bertini, 1951: 51); "En la Revista Contemporánea (primero o segundo año) salieron algunas muestras excelentes de una traducción completa de Leopardi que tiene hecha Pepe Alcalá Galiano, el cual está ahora de cónsul en Newcastle. Es amigo mío y creo que no tendrá inconveniente en facilitarnos alguna oda, para el ramillete que vas formando. Yo traduje y publiqué hace bastante tiempo en un periódico la Palinodia de Leopardi. No salió a mi gusto y por eso no la he incluido en ninguna de mis colecciones, pero si la encuentro y la arreglo un poco, también te la mandaré. De Leopardi convendría poner cuatro o cinco cosas, cada una por un traductor distinto. Tengo uno americano de mucho mérito, D. Calixto Oyuela, de Buenos Aires" (carta de 28 de mayo de 1886, en Bertini, 1951: 52). Estelrich hizo caso a las recomendaciones de Menéndez Pelayo, y Carmen de Burgos incluye en su propia selección hasta la Palinodia mencionada.

${ }^{36}$ Una sola muestra de cómo a principios del siglo XX se aprecia ya a Leopardi como autor de diálogos puede verse en "La sombra de Leopardi" de un escritor muy diferente a Carmen de Burgos, por su autosolemnidad y academicismo: Ricardo León (1920: 55-70), donde dos voces de poetas debaten sobre la condición melancólica y pesimista del escritor de genio y talento, lo que se entremezcla en la discusión con conceptos coetáneos de prestigio (idea de progreso, teoría de la evolución de las especies). De nuevo incluye una alusión a Leopardi en p. 81, en el diálogo "Del arte de vivir", y otra en p. 125, en "Jardines de selección". Véanse los textos y los registros publicados por González Soriano (2017: núms. 293 a 306) en Dialogyca BDDH.

UNED. REI, 6 (2018), pp. 37-87

ISSN 2340-9029 
$\mathrm{ta}^{37}$. Colombine trabajaba paralelamente en él (su biografía y obra) y en $\mathrm{La}$ voz de los muertos, según confesión propia:

Envuelta en la vorágine literaria, me salen dos nuevos libros, aunque por diferentes caminos. Uno se lo propongo yo a Sempere, y lo titulo "La voz de los muertos". Es producto quizás de mi extensa dedicación a Leopardi y fruto de su influencia, pues me salió del alma cuando trabajaba con sus poemas. Incluso copié su estilo, no lo oculto, pero hay en ellos una sinceridad que puede explicar mucho más sobre esta etapa de mi vida que cualquier comentario añadido que yo pueda hacerle. El libro se compone básicamente de diálogos entre diferentes personajes reales o inventados, y se inicia con uno preliminar entre la $\mathrm{Au}$ tora y su Genio Familiar ${ }^{38}$.

En efecto, como vimos al principio, de una de sus veinticuatro Operette morali (1824, con añadidos hasta 1832), el "Dialogo di Torquato Tasso

${ }^{37}$ Además del "Diálogo de Malambruno y Farfarello" en versión de Baráibar, ya citado, "Copernico" contó al menos con dos traducciones singulares, una de J. O’Neille (1876: 287-300), y otra de M. de la Revilla (1878: 326-336). El "Diálogo entre un vendedor de almanaques y un transeunte" se publica en traducción anónima [¿de Luis Ruiz Contreras?] en (1899). Son solo sueltas. Entre las traducciones de época, solo conozco una decimonónica francesa que pudiera haber estado al alcance de Colombine: Leopardi (1880). La fecha de esta otra versión española (solo de los diálogos, obra de Luis Cánovas) es incierta, probablemente 1883: c.f. Leopardi ([1883]). En español, como en otras lenguas, las traducciones del recanatense han sido con frecuencia y hasta hoy antológicas; cf. por ejemplo, Leopardi (2000). La edición bonaerense de 2015 se presenta como única integral en lengua española: en la ed. original de las Operette de 1827, la última pieza era el Dialogo di Timandro e di Eleandro y en la ed. de 1834 el Dialogo di Tristano e di un amico, buena condensación de su pensamiento; la traducción de A. P. Patat (Leopardi 2015) añade un apéndice con el texto excluido de la edición italiana de 1835 (por recusación del autor) titulado Dialogo di un lettore di umanità e di Sallustio; pero Carmen de Burgos sí lo había incluido ("Diálogo entre un lector de humanidades y Salustio", en Leopardi-Burgos, s.a. [1911?]: II, 105-106), lo que parece ser indicio de que ya no se maneja la versión de Colombine. La más reciente traducción antológica es muy reducida: Leopardi, 2016. La última versión española que conozco es: Leopardi (2017). Otra versión alemana antológica en Leopardi (1979).

${ }^{38}$ A continuación sigue el texto del diálogo citado (Utrera, 1988: 207). e del suo genio familiare" -calificado de "spirito"-, tomó inspiración obvia para el diálogo "Preliminar. La Autora y su Genio familiar”. Pero solo se sirvió del recurso externo, pues las diferencias son muy notables: los personajes leopardianos, en la prisión alegórica de la enfermedad de Tasso, dialogan sobre el placer como nostalgia del pasado o esperanza del futuro, nunca como experiencia plena del presente, mientras que los personajes de Colombine disertan sobre el planteamiento y objetivos de esos diálogos que se van a leer, su poética, las opciones de escritura de que dispone o la protección de las lenguas maldicientes. Leopardi desarrollaba el tema omnipresente de la facultad humana para ser feliz ${ }^{39}$, teorizaba el taedium vitae ${ }^{40}$, mencionaba

${ }^{39}$ Salvo excepciones y por motivos de espacio cito siempre solo por la versión española de la propia Colombine: "Diálogo entre Torcuato Tasso y su Genio familiar", en Leopardi-Burgos (s.a. [1911?]: II, 41-46). En este caso, Torcuato recuerda a su amada Leonora y eso le hace olvidar temporalmente las maldades de los hombres y las calamidades del mundo. Contiene una interesante discusión sobre la perfección o imperfección de la amada divinizada, con aportaciones sobre todo del Genio. Se equiparan los placeres verdaderos y los soñados. Dice el genio: "Sabe que de lo verdadero a lo soñado no hay otra diferencia sino que este puede algunas veces ser mucho más bello y más dulce, mientras que aquél no puede nunca" (íbid.: 42). Se discute del placer como concepto especulativo, no como sentimiento; irrealizable de forma completa para dejar al menos la esperanza de gozarlo en otra situación: "G. - . . que el placer es siempre pasado o futuro, pero nunca presente. T. - Que es como decir que no existe. G.--Así parece. T.—¿Ni siquiera en los sueños? G.—Propiamente hablando." (íbid.: 44). Equiparar placer y felicidad tiene consecuencias: "T.--He aquí por dónde nuestra vida, faltando siempre a su fin, es de continuo imperfecta, y el vivir por su propia naturaleza es un estado violento." (íbid.: 44).

40 "G._-iQué es el fastidio? T.-Aquí la experiencia no me falta para contestar a tu pregunta; me parece que el fastidio está en la naturaleza del ambiente, el cual llena todos los espacios interpuestos entre las cosas materiales y todos los huecos contenidos en cada una de ellas, y donde un cuerpo se va y otro no ocupa aquel lugar, él le sucede inmediatamente. Así, todos los intervalos de la vida humana, entre el placer y el disgusto, están ocupados por el fastidio, y sin embargo, como en el mundo material, según los peripatéticos, no se da descanso alguno, así en nuestra vida no se da descanso sino cuando la mente, por alguna causa, interrumpe el uso del pensamiento. En todo el resto del tiempo, el ánimo, considerado aún en sí propio y como separado del cuerpo, se encuentra que contiene algunas pasiones, como aquellas que al estar vacío de todo placer o disgusto supone el estar lleno de fastidio, el cual también es pasión, no menos que el dolor y el deleite. G.- [...] Verdaderamente, por fastidio no creo que deba entenderse otra cosa que el deseo puro de la felicidad no satisfecho por el pla- 
los posibles y escasos remedios ${ }^{41}$, y acababa con una traviesa suspensión escéptica:

T.-Adiós; pero oye: tu conversación me consuela bastante [...]; así, de ahora en adelante, para que te pueda llamar y encontrar cuando lo necesite, dime dónde tienes costumbre de habitar.

G.- ¿Todavía no me habías conocido? En cualquier licor generoso. (Leopardi-Burgos, s.a. [1911?]: II, 46).

Las disquisiciones finales del "Diálogo entre la Autora y su Genio familiar” de Carmen de Burgos, en cambio, recuerdan más a un pasaje del Zibaldone:

Per tanto i diversi modi di essere della materia, i quali si veggono in quelle che noi chiamiamo creature materiali, sono caduchi e passeggeri; ma niun segno di caducità né di mortalità si scuopre nella materia universalmente, e però niun segno che ella sia cominciata, né che ad essere le bisognasse o pur le bisogni alcuna causa o forza fuori di se. Il mondo, cioè l'essere della materia in un cotal modo, è cosa incominciata e caduca (Leopardi, 2013: $578)$.

Asimismo, la alusión a la relatividad y caducidad de los grandes conceptos, que cambian de significado a lo largo del tiempo, proviene seguramente del "Diálogo entre un Lector de Humanidades y Salustio" (Leopardi-Burgos, s.a. [1911?]: II, 105-106): a cuenta de una duda del Lector sobre la figura de la gradación, los dos interlocutores discuten si el orden adecuado es riqueza-honor-gloria-libertad-patria. El Lector critica:

cer ni tampoco rechazado abiertamente por el disgusto, cuyo deseo, como decíamos poco antes, no se ha satisfecho nunca y el placer propiamente no se encuentra; así es que la vida humana está compuesta en parte de dolores y en parte de fastidio, y cada una de estas pasiones no tiene reposo sino cediendo el puesto a la otra, y este no es tu destino particular, sino el común a todos los hombres." (ibid.: 44-45).

${ }^{41}$ Los remedios contra el fastidio son, según el Genio, "el sueño, el opio y el dolor" (íbid.: 45). Torcuato prefiere cambiar por "la variedad en las acciones, en las ocupaciones y en los sentimientos" (íbid.: 45) que aligeran, aunque no eliminen, el fastidio. La soledad ayuda a la distancia de las cosas humanas y así a valorarlas menos miserables, según el Genio. Pero Torcuato ha gustado de la conversación con él.
En suma, la cosa que colocas en lo último no solo no es mayor que todas las otras, sino que desde hace gran tiempo, ni siquiera existe; las otras valen cada una más que la que le sigue, y la primera es tal, que los hombres, por obtenerla, están prontos a dar siempre y en todas ocasiones la patria, la libertad, la gloria y el honor, que son las otras que tú pones y das todas en una hoja, y al hacer la unión ocurre esto. (Leopardi-Burgos, s.a. [1911?]: II, 106).

Salustio afirma entonces lo que da argumento a Colombine para un pasaje de su "Diálogo entre la Autora y su Genio Familiar" 42 . El nuevo orden de la frase pone las cosas en su sitio y permite ver que, en efecto, los grandes conceptos se entienden de manera diferente con el paso del tiempo ${ }^{43}$.

Aunque el escrutinio no debe quedar ahí, lo más verosímil es que el punto de partida de los diálogos de Burgos y el interés por esa tradición sea desde luego Leopardi, pues el poeta de Recanati era también apreciado filólogo y conocía muy bien a todos los autores citados, o si no más o menos frecuentados, por Colombine. Admiró a Fontenelle $e^{44}$, Voltaire ${ }^{45} \mathrm{o}$

42 "S.-Quizás pudiera responderte que de algún tiempo a esta parte han cambiado las opiniones y las costumbres acerca de lo que dices. Pero de todos modos, tu discurso me capacita, y así, borra este pasaje y vuélvelo a escribir como te he dicho" (Leopardi-Burgos, s.a. [1911?]: II, 106).

${ }^{43}$ Así lo recoge Colombine: "Hay verdades que se deben decir y conceptos abstractos que se necesita fijar: Honor, Gloria, Amor, Inmortalidad, Virtud, Patria... ¿No cambian de significado las palabras en el vocabulario? Pues si esto sucede y la palabra no es más que el signo de la idea, es indudable que las ideas han cambiado y que se necesita examinar lo que significan ya entre nosotros." (Burgos [1911]: 11).

${ }^{44}$ Para la influencia de los Entretiens sur la pluralité des mondes (1686) de Fontenelle en Leopardi, cf. entre otros Polizzi (2008: 55-102).

${ }^{45}$ Leopardi cita o nombra a menudo (una treintena larga de veces) a Voltaire en el Zibaldone; la mayoría son menciones muy genéricas. Para el conjunto de influencias de Voltaire sobre las Operette, cf. la síntesis de Cellerino (1995: en especial 312-318). El tipo de alusiones leopardianas que selecciona, a su vez, Carmen de Burgos son como esta: "la Revolución estaba en las almas, en el espíritu colectivo de aquel pueblo que recibía a Voltaire, su verbo, con honores reales, y próximo a hacer caer la cabeza y la corona de sus reyes, ceñía otra corona a la frente del viejo filósofo..." (LeopardiBurgos, s.a. [1911?]: I, 46). Sebastiano Timpanaro (1979) define así las primeras Ope- 
Parini ${ }^{46}$ y había estudiado a fondo el pensamiento y la literatura griegos ${ }^{47}$. Aun así siguen percibiéndose en la crítica resistencias a entender y analizar estas obritas leopardianas como diálogos; por ejemplo, se defiende su dimensión teatral hasta oscurecer las características inherentes al género decidido y otorgado por el autor, género que une desde sus orígenes la condición argumentativa y la dramática ${ }^{48}$.

Por Luciano y por la sátira menipea da Leopardi frecuentes muestras de aprecio, y define sus diálogos como "Dialoghi Satirici alla maniera di Luciano". A la vez que se separa de la tradición imitativa de los Dialoghi mortuorum, ya entonces banalizada, estima de Luciano precisamente su crítica negativa generalizada, sin paliativos ni alternativas, de las cuestiones importantes de la condición humana, punto de vista que él mismo distingue de otros imitadores de su periodo, como Vincenzo Monti:

Dialoghi Satirici alla maniera di Luciano, ma tolti i personaggi e il ridicolo dai costumi presenti o moderni, e non tanto tra morti, giacchè di Dialoghi de’ morti cè molta abbondanza, quanto tra personaggi che si fingano vivi, ed anche volendo, fra animali; (come sento che n'abbia fatto il Monti imitatore di Luciano anche nel Dialogo della Bibl. Italiana). ${ }^{49}$

Valora la capacidad del samosatense para servirse de un observador externo privilegiado o de un animal parlante que comenta, parodia, satiriza o denuncia un tema o situación; gusta de la mezcla de géneros, voces y tiempos propia de la menipea, y de sus puestas en escena fantásticas

rette morali: "a series of prose sketches that were 'philosophical' after the manner of Voltaire and the French philosophes of the 18th century".

${ }^{46}$ Además de menciones más dispersas destaca su opúsculo ya citado "Parini ovvero Della gloria".

${ }^{47}$ Para la importancia seminal del pesimismo griego en Leopardi -sobre todo en su, en este aspecto, desatendida prosa- $y$, a través de él, en la historia intelectual moderna de Europa, cf. Franzoni (2017).

${ }^{48}$ Un solo ejemplo: el volumen La dimensione teatrale in Giacomo Leopardi... (Centro nazionale di studi leopardiani, 2008).

${ }^{49}$ Nota de Leopardi en 1819 a las Operette (en Leopardi, 2013: 1109). Monti prefirió limitar sus piececitas lucianescas a la crítica de cuestiones lingüísticas de la Accademia della Crusca.
(Weinbrot, 2005: 110). En sustancia, Leopardi -y no Carmen de Burgosconsidera ya manida la subtradición de coloquios de muertos, pero se une a Luciano en importantes aspectos formales (género del diálogo, humor e ironía menipeos, tipo de personajes, estilo) e ideológicos (denuncia de la insignificancia y las futilidades humanas, postulados filosóficos e intelectuales como la negación del antropocentrismo, parte de la teoría del placer, sátira de la religión, decepción de la humanidad misma -no solo género humano decepcionante-, etc. $)^{50}$.

Leopardi enfrenta en sus invenciones fantásticas solo ocasionalmente a "Antiguos" y "Modernos" ("Dialogo di un Lettore di umanità e di Sallustio", "Dialogo di Malambruno e Farfarello") pues, aunque se confiese lucianista, ya no se preocupa por esa querella como Fontenelle. Pero cuando sí la introduce, toma partido por los antiguos ${ }^{51}$. Colombine debió de heredar de él su querencia por el mundo clásico que ella expresa en términos muy generales (“...busqué la clásica pureza y sencillez de la línea griega. La música primitiva, que con tan pocas notas supo dar todas las impresiones”, Burgos [1911]: 10-11) a través de personajes leopardianos como Hércules y Atlante, Timandro y Eleandro, Porfirio y Plotino, o Salustio.

Tampoco los dialogantes de Leopardi son necesariamente figuras históricas ni personajes muertos (un Físico y un Metafísico, un Vendedor de almanaques y un Transeúnte), sino protagonistas de su tiempo con vicios comunes que hay que corregir y que responden a aspectos básicos del sistema filosófico del autor (indolencia, vana presunción, vulgaridad, ilusión o ignorancia, impostura, apariencia, maldad, taedium vitae, infe-

${ }^{50}$ Sobre la deuda de las Operette de Leopardi a Luciano cf., entre otros, Sangirardi (1998: 305-383) y (2001: 25-86); Scheel (1995: 25-31), y otros trabajos de las mismas actas. Antes, destaca sobre todo el análisis del gran estudioso del lucianismo italiano, Mattioli (2008: 75-98). Franzoni (2017: 55-68), en el cap. II de su tesis, se ocupa del lugar que representa Leopardi en la recepción de Luciano.

${ }^{51}$ Franzoni, 2016: 47-48: "as a defender of antiquity himself, he can do what the Anciens had entirely failed to do, that is to defend and support the ancients precisely for their dolorous and brave worldview. This - their pessimistic Weltanschauung - is the reason antiquity beats modernity, and the reason modernity ought to look back and up to the past's insights".

UNED. REI, 6 (2018), pp. 37-87

ISSN 2340-9029 
licidad existencial); son muestras representativas los anteriores ejemplos citados y el Islandés, el Amigo de Tristán o el Lector de Humanidades.

Al rechazar el optimismo filosófico antropocéntrico del ochocientos y su idea de progreso, o presentar nociones como la felicidad o la inmortalidad del alma desde el puro ateísmo, muchos personajes de Leopardi son observadores críticos y satíricos del género humano, no solo ni principalmente retratos de tipos representativos que hablan de sí mismos, como algunos o muchos de los de Colombine o Fontenelle. Hay interlocutores mitológicos (Ercole, Atlante, Prometeo, Momo), literarios (el Malambruno del Quijote o el Farfarello de Dante) y de cuento (Folletto, Gnomo), personajes históricos (Cristoforo Colombo, Pietro Gutiérrez, Federico Ruysch, Copernico, Murco senatore romano) -entre ellos escritores y filósofos (Torquato Tasso, Timandro, Eleandro, Plotino, Porfirio, Sallustio)-, personificaciones de abstractos (Moda, Morte, Natura, Anima, Terra, Luna, Ora prima, Sole, Mondo), animales (Cavallo, Toro, Bue), personajes representativos de nacionalidad, estado, oficio o profesión -aunque no sean solo eso- (Islandese, Venditore di almanacchi, Passeggere, Selvaggio, un Famiglio, Fisico, Metafisico, Lettore di umanità, Filosofo greco, Senatore romano, Galantuomo), y a menudo la opinión autorial se proyecta en uno de ellos (el caso más notable es Tristano), o en los dos. Para dar prioridad a la argumentación desnuda, en estado puro, los espacios no importan salvo muy excepcionalmente: el hypernéphelos del Icaromenipo lucianesco es un recuerdo en la obrita La scommesa di Prometeo $^{52}$.

Dado que Leopardi descartó en lo fundamental la subtradición lucianesca de diálogos de muertos, quizás Carmen de Burgos tomó la idea de dar voz a los muertos no solo de Fontenelle, sino del "Dialogo di Federico Ruysch e delle sue mummie" ("Dialogo entre Federico Ruysch y sus Momias", Leopardi-Burgos, s.a. [1911?]: II, 53-57), donde un coro de muertos en el estudio del anatomista, fisiólogo, arqueólogo y botánico holandés ha

\footnotetext{
${ }^{52}$ Carmen de Burgos comete un error reiterado al traducir La scommesa di Prometeo ("La apuesta de Prometeo"): "Impernéfelo" por "Hipernéfelo" de Luciano, indicio probable bien del desconocimiento directo del texto del samosatense o al menos de su comprensión cuidadosa.
}

resucitado y "cantan a media noche como gallos" (íbid.: 53) ${ }^{53}$. Estos difuntos tienen "facultad [de hablar] por un cuarto de hora" (íbid.: 54): "M.-Nosotros no podemos hablar más que respondiendo a alguna persona viva. Quien no ha de contestar a los vivos, acabada la canción enmudece" (íbid.: 54-55). Algunas de sus afirmaciones se aprovechan en otros lugares de $\mathrm{La}$ voz de los muertos, como por ejemplo, la idea de que ellos no recuerdan el instante de la muerte, que es indolora, porque la separación de alma y cuerpo es un momento dulce:

B.-Entonces si no es dolor, ¿qué es la muerte?

M.-El más grande de los placeres. [...] (Leopardi-Burgos, s.a.

[1911?]: II, 55)

Como siempre, el final es inquietante y deja a la vez asomar el humor leopardiano ${ }^{54}$, pues no se debe confundir su pesimismo con una actitud resignada y de aceptación ${ }^{55}$. Es una postura rebelde, no integradora.

Colombine coincide con Leopardi en que el retrato de los personajes debe entenderse como algo distinto del personaje real, no como su duplicado naturalista. Aparte, las convergencias ideológicas parciales se prodigan.

${ }^{53}$ Dice un Muerto: "Hace poco, cerca de media noche, se ha cumplido por primera vez aquel año grande y matemático, sobre el cual escribieron tantas cosas los antiguos, y esta es igualmente la vez primera que los muertos hablan. Y no solo nosotros, sino en todo cementerio, en todo sepulcro, en el fondo del mar, la nieve y la tierra, en cielo abierto o en cualquier lugar que se encuentren todos los muertos, hacia la media noche han cantado como nosotros la cancioncilla que has escuchado." (LeopardiBurgos, s.a. [1911?]: II, 54).

54 "R.-Así dice Cicerón que ninguno, por viejo que sea, deja de prometerse algunos años de vida. ¿Pero cómo comprendisteis, por último, que el espíritu había salido del cuerpo? Decid: ¿cómo conocisteis que habíais muerto? No responden. Hijitos, ¿no me oís? Habrá pasado el cuarto de hora. Movámoslos un poco. Están bien remuertos, no hay peligro de que me den miedo otra vez. Volvamos al lecho." (Leopardi-Burgos, s.a. [1911?]: II, 57).

${ }_{55}$ De hecho, hay constancia léxica de lo abigarrado de los conceptos: cf. Allegrini (2017: 1-12): el estudio de las ocurrencias de la palabra 'disperazione' en la prosa leopardiana revela una pluralidad de significados que no excluyen la compañía del placer, la risa o el humor y la esperanza.

UNED. REI, 6 (2018), pp. 37-87

ISSN 2340-9029 
Algunas de las grandes preguntas metafísicas y éticas del Leopardi materialista calan en $L a$ voz de los muertos. El sentido de la existencia en un universo sin trascendencia, como el de Leopardi, solo se explica a sí mismo (Consiglio, 2014: 157-172). El ser humano, animal inerme, insignificante y tosco, no el centro de la creación como él mismo supone, es una víctima de la Naturaleza indiferente. La culpa en Leopardi no tiene sentido trascendente, y tampoco el arte es redentor, pues es solo un recreo solipsista. El tedio vital acompaña esta concepción nihilista de la vida, el hombre debe lamentar haber nacido, como en la máxima de Crántor; está condenado a la desdicha permanente -porque su deseo de infinito y de eternidad es inalcanzable- y el único paliativo modesto es la solidaridad humana frente al poder de la Naturaleza. Su tragedia existencial supone la imposibilidad de llevar una vida placentera y la incomprensión del porqué de ese sufrimiento inútil. La única salida rebelde es el suicidio y, en términos menos violentos, el humor. La idea se verbaliza con nitidez en el "Diálogo entre Timandro y Eleandro"

La teoría del placer leopardiana es la proporción entre el amor de sí mismo (o cuidado de sí, o vida interior, o actividad de la mente) y la infelicidad del hombre (Franzoni, 2017: 91), que es el animal con más vida reflexiva e interior y por ello el que más sufre. Leopardi se sitúa en un plano ontológico y lo que diferencia al hombre de otras criaturas es la emoción, la autoconciencia, la razón, sede de su sufrimiento por no aceptar sus propios límites. En "El Copérnico" (Leopardi-Burgos, s.a. [1911?]: II, 72-81), el Sol, harto de girar, decide que en adelante lo haga la Tierra, y pone en ridículo a la especie humana como centro del universo a la vez que se ríe de poetas y filósofos ${ }^{57}$. El hombre no es el único ser vivo y en el "Dialogo

${ }^{56}$ En el "Diálogo entre Timandro ['crítico'] y Eleandro ['escritor']” (Leopardi-Burgos, s.a. [1911?]: II, 63-71), el primero censura al segundo el que siempre critique al género humano, y le invita a alabarlo. Eleandro no ve razones para hacerlo, pues la raza humana es infeliz, y solo cree posible apaciguar los ánimos con la risa. La felicidad del hombre, según los filósofos, viene de su capacidad de conocer la verdad, mientras que la infelicidad procede de su ignorancia y su vivir de la apariencia. La filosofía es dañosísima. Hay más placer en el espíritu que en el cuerpo. Si el hombre fuera perfecto escribiría sobre ello.

${ }^{57}$ En la escena $4^{\text {a }}$ hablan Copérnico y el Sol, y el filósofo intenta persuadir al Sol di un Folleto e di uno Gnomo" ha desaparecido incluso del mundo sin mayores consecuencias. La irrealidad y condición fantástica o legendaria de los personajes ayuda a plantear cuestiones esenciales de la vida humana, que los dos dialogantes son capaces de observar y juzgar. En el sarcástico "Diálogo entre Plotino y Porfirio" la única superioridad del hombre sobre otras criaturas es precisamente la razón de su miseria existencial y su dolor. Lo mismo pasa en el Dialogo tra due bestie p.e. un Cavallo e un Toro (1820) o en el Dialogo di un Cavallo e un Bue que Colombine no traduce. Aunque las ideas que Leopardi hace defender a los animales dialogantes sí se vuelcan en La voz de los muertos, es curioso que su autora se desentienda de los coloquios de animales, de fructífero linaje desde antiguo ${ }^{58}$.

En "Diálogo entre la Naturaleza y un Islandés" (Leopardi-Burgos, s.a. [1911?]: II, 47-52), con verba dicendi al final, vuelve a tratar sobre la felicidad; el Islandés va huyendo de Naturaleza, y hace un alegato contra ella quejándose de la infelicidad del ser humano; su interlocutora entiende que el motivo está en considerarse el único o más importante de los seres creados, idea que retoma Carmen de Burgos en varios de sus textos.

N.-Tú demuestras no haber pensado que la vida de este universo es un perfecto circuito de producción y destrucción, ligadas ambas entre sí de manera que cada una sirve continuamente a la otra para la conservación del mundo, el cual, cuando cesase alguna de ellas, se destruiría rápidamente. Por tanto, resultaría en su daño que hubiese alguna cosa libre de padecimiento.

I.-Lo mismo oigo decir a todos los filósofos; mas puesto que el que es destruido padece y el que destruye no goza y poco después es destruido igualmente, dime esto que ningún filósofo me sabe decir: ¿Quién se recrea y quién goza con esta vida infelicísima del universo conservada a costa del daño y de la muerte de todas las cosas que le componen? (Leopardi-Burgos, s.a. [1911?]: II, 52).

de las dificultades que tendría la empresa de convencer a la Tierra para que sea ella quien gire; pero el Sol insiste y Copérnico se pliega, pidiendo que le ayude en la última dificultad: que no le quemen. El Sol le recomienda dedicar su libro al papa. ${ }^{58}$ Prescinde también del boceto Dialogo tra un Filosofo greco, Murco Senatore romano, Popolo romano, Congiurati.

UNED. REI, 6 (2018), pp. 37-87

ISSN 2340-9029 
El cierre, de nuevo rociado de humor escéptico, explica en voz del narrador el final incierto del Islandés, víctima en cualquier caso de la crueldad de Natura: bien se lo comieron dos leones hambrientos o bien acabó, sepultado por el viento en la arena, convertido en momia y conducido a un museo de una ciudad europea.

En el "Diálogo entre Tristán y un Amigo" (Leopardi-Burgos, s.a. [1911?]: II, 97-104), el Amigo encuentra a Tristán 'meláncólico’ y este, manejando la ironía, le explica que ha cambiado de opinión desde que escribió su libro sobre la infelicidad del hombre. A través de la paradoja, resumiendo lo que en otro tiempo pensaba, Tristán defiende que los hombres se creen felices "porque, en substancia, el género humano cree siempre, no la verdad, sino aquello que es o parece ser más a propósito para él." (íbid.: 98), en especial los no formados, que creen necedades; él sostiene una "filosofía dolorosa, pero verdadera", y después averigua que no es muy original:

... que Salomón, y Homero, y los poetas y los filósofos más antiguos que se conocen, todos están llenos, llenísimos de figuras, de fábulas, de sentencias significativas de la extremada infelicidad humana, y de las que se deduce que el hombre es el más mísero de los animales; que dice que lo mejor es no nacer, y puesto que se ha nacido, morir en la cuna; otros, que uno que sea escogido por los dioses, muere en su juventud, y otras muchas cosas infinitas a este tenor. (Leopardi-Burgos, s.a. [1911?]: II, 99).

Compara los siglos, vencen los antiguos frente a la mediocridad presente, se ríe del progreso en el que creen sus coetáneos y de sí mismo por haber malgastado el tiempo en estudio, esperanza de gloria y de inmortalidad; a Tristán no le preocupa que quemen su libro o lo dejen como la curiosidad producida por un enfermo "desgraciadísimo" que solo aspira, como elemento consolatorio y como refugio, a la muerte. Y en analogía con el "Diálogo entre Plotino y Profirio" acaba:

Este es el único beneficio que puede reconciliarme con el destino. Si me fuese propuesta por un lado la fama y la fortuna de César o de Alejandro, limpias de toda mancha, y por otro el morir hoy, y hubiese de escoger, yo diría que morir hoy, y no querría tiempo para meditar. (Leopardi-Burgos, s.a. [1911?]: 104).

Carmen de Burgos concuerda con Leopardi en que su tentativa es eudaimonista -en términos de Sigurðsson (2010: 12)-, ya que cree que la vida humana tiene como único objetivo la felicidad e identifica felicidad con placeres, lo que también implica al deseo ${ }^{59}$. Esa posición se combina con relativismo epistemológico, filosófico y moral, y hereda también las deudas conflictivas leopardianas tanto con la Ilustración como con el Romanticismo. Leopardi es antiplatónico y antikantiano (Sigurðsson, 2010: 12), lo que recibe Colombine; pero él prefiere, como dicen entre Timandro y Eleandro, reir solidariamente, entre semejantes, de los dolores comunes, antes que convencer a los otros de su existencia; a esto último, en cambio, no renuncia la Colombine educadora. De hecho, la mención de Platón en boca de Carmen de Burgos en su diálogo preliminar, solo se puede entender como referente dialogal, literario, no filosófico. En el "Diálogo entre Plotino y Porfirio" (Leopardi-Burgos, s.a. [1911?]: II, 82-94) de Leopardi, Porfirio, el neoplatónico más joven, desea el suicidio y su maestro Plotino, que se ha dado cuenta, intenta evitarlo. Platón le sirve a Porfirio para la vida de las escuelas, pero no para la práctica. Platón es más cruel que Naturaleza y Destino porque sus promesas de inmortalidad (Eliseo, Tártaro) son aún más infelices que la infeliz vida (íbid.: 86). Él fue el causante de que la duda del hombre (si es lícito o no quitarse la vida) lo haga infeliz. El mensaje final de Plotino es que su interlocutor abandone la idea del

${ }^{59}$ Puede adivinarse eudaimonismo hasta en detalles menudos: en el "Diálogo entre Cristóbal Colón y Pedro Gutiérrez" (Leopardi-Burgos, s.a. [1911?]: II, 58-62), vuelven los temas recurrentes de incertidumbre y deseo: Colón expone sus dudas sobre la tierra descubierta ante Gutiérrez, en medio del mar, en el navío de viaje, y discurren sobre el único deseo: ver tierra. En el Dialogo di un venditore d'almanacchi e di un passeggere -el más difundido de Leopardi para expresar su pensamiento, junto con el Dialogo della Natura e di un islandese-, se produce un encuentro casual entre los personajes; el que más habla es el transeúnte, que interroga al vendedor inculto sobre la felicidad; en la vida la esperanza no considera pasado ni presente sino solo futuro como aspiración de felicidad: “... si ha sufrido teniendo la vida anterior con todo su bien y su mal, nadie querría renacer. La vida, que es una cosa bella, no es la vida que se conoce, sino la que se ignora; no la vida pasada, sino la futura..." ("Diálogo entre un Vendedor de almanaques y un Transeúnte”, íbid.: 95-96, en 96).

UNED. REI, 6 (2018), pp. 37-87

ISSN 2340-9029 
suicidio, que se consuelen juntos y piensen que, al morir, serán recordados por los amigos con amor (íbid.: 94; "attendiamo a tenerci compagnia l'un l'altro; e andiamoci incoraggiando e dando mano e soccorso scambievolmente; per compiere nel miglior modo questa fatica della vita").

Colombine también concuerda en la idea de que el progreso real es la búsqueda de la verdad fundada en el respeto a la razón y la colaboración solidaria entre los seres humanos (“... la idea es lo único grande, lo único inmortal”, dice Carmen de Burgos) ${ }^{60}$. La muerte es, igualmente, liberación y cese del dolor vital ("La existencia es inevitable a la materia. Al desaparecer la forma humana seguiremos existiendo como parte de la Naturaleza, pero quizás acabe el dolor en la tierra”, Burgos [1911]: 12). Se perciben algunos préstamos concretos que toma del italiano ${ }^{61}$. En ambos se advierte formación filosófica materialista e hincapié en los sentidos, pero Carmen de Burgos no comparte el tantas veces repetido "pesimismo histórico" y "cósmico" del poeta italiano (con una visión destructiva de la naturaleza indiferente y un mecanicismo radical), y se mueve mejor en una perspectiva subjetiva de protesta ética, social, política y civil, que tamiza mucho más el pesimismo subyacente $^{62}$. Leopardi extrapola la situación al conjunto del género humano o a la condición humana; Colombine tiene más interés en presentar tipos concretos responsables (y representativos) de prejuicios censurables. Los

${ }^{60}$ Carmen de Burgos, Diario de Almería, 22-IX-1931. Lo tomo de Núñez, 1992: 88. ${ }^{61}$ Me refiero ahora no a las muchas recurrencias ya vistas sino a algunos pensamientos dichos a vuelapluma, que también son de linaje leopardiano, del tipo: "Gloria sin calumnia no puede existir" (Burgos [2011]: 99) e ibid., la alusión irónica a "doña Moda".

${ }^{62}$ Núñez, 1992: 136: "Lo cierto es que su modelo literario se acerca más al de Leopardi, con el que comparte la presencia del sentimiento, la visión pesimista, un cierto escepticismo, la ironía crítica o satírica, incluso alguna vez cierto tono de parodia frente a la alta dignidad del diálogo clásico (Leopardi enfrenta en diálogo a "Un Vendedor de almanaques y un Transeúnte")". Esa práctica no depende solo de Leopardi sino de toda la tradición lucianesca. Luciano permitía incorporar todos o muchos elementos de la cultura clásica sin situarse en una actitud reverencial hacia el clasicismo, sino más bien desde la parodia y el spudogéloion. Lo mismo hicieron la mayoría de sus imitadores a lo largo de los tiempos. dos conducen la ironía hasta la frontera de lo grotesco, pero hay mucha más esperanza regeneracionista y pedagógica en Carmen de Burgos ${ }^{63}$.

Leopardi revisó minuciosamente sus Operette desde el punto de vista estilístico, tanto la selección léxica como los recursos empleados para dar desenvoltura e ingenio al diálogo. Su estilo irónico de escuela clásica no pierde el humor en Colombine (Burgos [1911]: 11), que dice imitarlo: la lengua de $L a$ voz de los muertos se carga de la naturalidad y sentimiento fuerte de los interlocutores que da esencialidad a los temas ${ }^{64}$. Es el mismo ideal de estilo de muchos imitadores de Luciano desde la segunda mitad del siglo XVII, que defienden, fuera de tiempo, como sus antecesores, la sprezzatura, y denuncian la pedantería de su época ${ }^{65}$ _“... la insoportable prosa negra de los eruditos", en palabras de Ramón Gómez de la Serna- ${ }^{66}$. Cuando Burgos dice que imita el estilo, hay que entender que concuerda con el empeño antipedantista de Leopardi en sus críticas lingüísticas ácidas al purismo y rigidez estilísticos de la Accademia della Crusca, la defensa de un nuevo canon o un nuevo clasicismo de la lengua más natural y transparente.

\section{Inquietudes y desvelos propios}

Pero, para terminar, por encima de los parecidos con sus referentes, Carmen de Burgos expresa preocupaciones propias que dudosamente

${ }^{63}$ Núñez (1992: 10) destaca a la regeneracionista, laica, racionalista y pedagoga, con el "idealismo de los librepensadores franceses"; y acota: "cree en la bondad natural del hombre, cree que la sociedad la pervierte, cree que el mal social proviene de la ignorancia y del oscurantismo, cree que la salvación se encuentra en la educación y el trabajo; defiende una existencia sana, en armonía con la naturaleza, ilustrada, luminosa y tolerante, y tiene esperanza, por todo ello, de la regeneración de España" (íbid.).

${ }^{64}$ Burgos tuvo amistad con Blasco Ibáñez (y hubo de negar los rumores de que eran amantes); algunas técnicas del Naturalismo influyeron sobre ella (Núñez, 1992: 23). Blasco era también amigo de Sempere y co-propietario de la editorial fundada en 1900 .

${ }^{65}$ A otros propósitos cf. Correard, 2011: 57.

${ }^{66}$ Ramón Gómez de la Serna, en Carmen de Burgos, Fígaro, Madrid, Imprenta "Alrededor del mundo", 1919, Apéndice de Ramón, p. 303; lo tomo de Núñez, 1992: 191.

UNED. REI, 6 (2018), pp. 37-87

ISSN 2340-9029 
compartieron sus modelos, algunos de ningún modo, otros al menos no de la misma manera. En particular en la vertiente de educación femenina, una de las principales inquietudes de Burgos, destacan temas de su actualidad estricta, como matrimonio, prostitución, igualdad de los sexos, divorcio, formación de las mujeres - las peores enemigas de sí mismas- y de los hijos, deberes de la maternidad y la paternidad, hipocresía y doble moral de la Iglesia, la legislación y la sociedad. Por ejemplo, se percibe su interés por mostrar cómo se abre camino en la discusión el papel de un hombre diferente y de una mujer nueva: en "La Galantería. Diálogo entre don Juan Tenorio y una Feminista" se dramatiza una doble oposición: de un lado, entre el varón galán pendenciero y el varón respetuoso; de otro, entre la mujer no formada e ingenua de tiempos de don Juan y la compañera del presente. Desea profundizar en las formas de concebir el amor de hombre y mujer y según edades de la vida. Le importan especialmente las cualidades de la mujer culta y su manera de entender el amor frente a la galantería. De modo análogo aparece la preocupación de la Carmen de Burgos educadora, siempre muy presente en particular referida a la educación femenina, en "El Romanticismo. Diálogo entre Lucrecia de Borgia y una Educanda de las Ursulinas"; el personaje más inquieto y preguntón es la ursulina, para escandalizarse y dar así ocasión a Lucrecia de eximirse o justificarse. La Borgia también pregunta a la ursulina al final, pero lo hace para poner de relieve sus contradicciones, apariencias, abulia cultural, hipocresía social y religiosa o destrucción moral que, a juicio de la autora, desvelan los usos amorosos y educación sentimental de la mujer aristócrata del periodo.

En definitiva, en La voz de los muertos preocupa la política, la moral y la educación mucho más intensamente, o con más urgencia y desasosiego que en cualquiera de sus modelos previos.

Recibido: $22 / 05 / 2018$

Aceptado: 24/09/2018

\section{Referencias bibliográficas}

Alfonso, Mercedes (2016), «Un ouvrage hybride: La voz de los muertos», en Constance et évolution d'une écriture engagée: l'oeuvre de Carmen de Burgos journaliste, essayiste et romancière, tesis doctoral, Université de Bourgogne, pp. 625-677 (https://tel.archives-ouvertes.fr/tel-01533561/, fecha de consulta: 1 junio 2017).

Allegrini, Vincenzo (2017), «Dicono $i$ poeti che la disperazione ha sempre nella bocca un sorriso. Per un'analisi semantica della disperazione in Leopardi», en L'Italianistica oggi: ricerca e didattica, Atti del XIX Congresso dell'ADI - Associazione degli Italianisti (Roma, 9-12 settembre 2015), a cura di B. Alfonzetti, T. Cancro, V. Di Iasio, E. Pietrobon, Roma: Adi editore, pp. 1-12. Asequible en red: http://www.italianisti.it/Atti-diCongresso?pg $=\mathrm{cms} \& \mathrm{ext}=\mathrm{p} \& \mathrm{cms} \_$codsec $=14 \& \mathrm{cms} \_$cod $\mathrm{cms}=896 \quad$ (fecha de consulta: 4 enero 2018).

Andries, Lise (2013), "Querelles et dialogues des morts au XVIII ${ }^{\mathrm{e}}$ siècle», Littératures classiques 81, 2, pp. 131-146 (asequible en: http://www.cairn. info/revue-litteratures-classiques-2013-2-page-131.htm). (13-IX-2014).

Bernier, Marc-André (2006), «Scepticisme et rhétorique du parallèle dans les Nouveaux dialogues des morts de Fontenelle», en M.-A. Bernier (éd.), Parallèle des Anciens et des Modernes, Québec: Presses Universitaires de Laval, pp. 49-62.

Bertini, Giuseppe Ma (1951), «Quattro lettere inedite di Marcelino Menéndez y Pelayo», Quaderni Ibero-Americani, 10, pp. 51-53.

Biblioteca Nacional de España (2016), «Información Bibliográfica» [de Carmen de Burgos] en la Hemeroteca Digital:

http://www.bne.es/es/Servicios/InformacionBibliografica/AutoresDominioPublico/Semblanzas/Carmen-de-Burgos/index.html (última consulta el 13 septiembre 2016).

Burgos, Carmen de (1909), «Giacomo Leopardi», Prometeo, II, 9 (julio). ---- ([s.a.] 1911?), Giacomo Leopardi (su vida y sus obras), Valencia: Sempere y Cía, s.a. [1911?], 2 vols.. Citado: Leopardi-Burgos [s.a., 1911?]. 
----- ([s.a.] 1911), La voz de los muertos, Valencia: Prometeo, s.a., asequible en: bdh-rd.bne.es/viewer.vm?id=0000076007\&page $=1$. Y Valencia: F. Sempere y Cía, 1911.

Bury, Emmanuel (2007), «Un sophiste impérial à l’Académie: Lucien en France au XVII ${ }^{\mathrm{e}}$ siècle», en Lucian of Samosata Vivus et Redivivus, eds. C. Ligota y L. Panizza, London: Warburg Institute, pp. 148-174.

Caballero, Fermín (1875), Conquenses ilustres, Madrid: Oficina Tipográfica del Hospicio.

Cazanave, Claire (2005), «Le dialogue au XVII ${ }^{\mathrm{e}}$ siècle: un genre moderne? Éléments pour une mise au point», XVII siècle, 228, pp. 427-442.

----- (2007a), Le Dialogue à l’âge classique, Paris: Champion, pp. 122-129.

----- (2007b), «Les Nouveaux dialogues des Morts de Fontenelle: les enjeux du renouvellement d'un genre», Otrante, 22, automne, pp. 73-84.

Cellerino, Liana (1995), «Operette morali di Giacomo Leopardi», en Letteratura italiana Einaudi, Le Opere III, Dall'Ottocento al Novecento, a cura di A. Asor Rosa, Torino: Einaudi, pp. 303-355.

Centro nazionale di studi leopardiani (ed.) (2008), La dimensione teatrale in Giacomo Leopardi: atti dell'XI Convegno internazionale di studi leopardiani, Recanati 30 settembre/ 1-2 ottobre 2004, Firenze: L. S. Olschki.

Colombo, Angelo (dir.) (2002), Lectures de Léopardi: petites œuvres morales, Rennes: Presses universitaires de Rennes.

Consiglio, Francesco (2014), «Giacomo Leopardi y el viaje hacia la nada. Una breve introducción filosófica», Disputatio. Philosophical Research Bulletin, 4, pp. 157-172. Salamanca-Madrid | www.disputatio.eu. ( fecha de consulta: 5 diciembre 2017).

Correard, Nicolas (2008), Rire et douter: lucianisme, scepticisme(s) et préhistoire du roman en Europe (XVe-XVIII ${ }^{e}$ s.), tesis doctoral inédita, dir. Fr. Lavocat, Université Paris Diderot - Paris 7.

----- (2011), «Le parallèle entre anciens et modernes dans les Nouveaux dialogues des morts de Fontenelle et l'instauration d'une poétique classique du genre ménippéen», Littératures classiques, 75, 2, pp. 51-70.
DeJean, Joan (1997), Ancients against Moderns: Culture Wars and the Making of a Fin de Siècle, Chicago: University of Chicago Press.

Del Gatto, Antonella (2001), Uno specchio d'acqua diaccia: sulla struttura dialogico-umoristica del testo leopardiano: dalle Operette morali ai Canti pisano-recanatesi, Firenze: F. Cesati.

Egilsrud, Johan S. (1934), Le «dialogue des morts» dans les littératures française, allemande et anglaise (1644-1789), Paris: L'Entente linotypiste.

Ena Bordonada, Ángela (2014), «Carmen de Burgos y Seguí "Colombine” (1867-1932)», en Carmen Servén (coord.), Escritoras en la prensa 1860-1936, Antología didáctica, Proyecto INV-00034 (Instituto de la Mujer, Ministerio de Sanidad y Asuntos Sociales/Fondos Feder, 2011-2013), en http://www.escritorasenlaprensa.es/carmen-de-burgos-y-segui/ (última consulta el 13 septiembre 2016).

Estelrich, Juan Luis (1889), Antología de poetas líricos italianos, Palma de Mallorca: Diputación Provincial de Baleares.

Ferraro, Giuseppe (1996), Il poeta e la filosofia: filosofia morale e religione in G. Leopardi: saggio di interpretazione, Napoli: Filema.

Ferretti, Giovanni (2017), «Giacomo Leopardi», en Enziclopedia Italiana: (http://www.treccani.it/enciclopedia/giacomoleopardi_\%28Enciclopedia-Italiana\%29/) [última consulta: 1 junio 2017].

Fontenelle, Bernard de $\left(1683^{3}\right)$, Les Nouveaux Dialogues des Morts, Paris: C. Blageart, $3^{\mathrm{e}}$. éd.

Fontenelle, [Bernard de, 1682] (1684), Deuxième partie y Jugement de Pluton, Paris: C. Blageart.

---- (2010), Nuevos diálogos de los muertos, ed. y trad. esp. de Ma Pilar Blanco García, Madrid: Cátedra (Letras Universales).

Fraga, María Jesús (2016), «Los textos dialogados en la Prensa española de finales del siglo XIX», AnMal Electrónica, 41, pp. 273-297.

Franzoni, Maria Giulia (2017), A philosophy as old as Homer: Giacomo Leopardi and greek poetic pessimism, $\mathrm{PhD}$ at the University of St Andrews (http://hdl.handle.net/10023/11357, última consulta 15 marzo 2018).

UNED. REI, 6 (2018), pp. 37-87

ISSN 2340-9029 
Gómez, Alberto Luis y Jesús Romero Morante (2006), «Divorciadora, profesora de Escuela Normal y Engel, [reseña con amplias notas a] Nuñez Rey, C. Colombine en la Edad de Plata de la literatura española», Biblio 3W Revista Bibliográfica de Geografía y Ciencias Sociales, Universidad de Barcelona, XI, n 631 (5 de febrero), [http://www.ub.es/geocrit/b3w-631.htm] (fecha de consulta: 5 diciembre 2017).

González Soriano, José Miguel (2018), «Ricardo León. La escuela de los sofistas», en Dialogyca BDDH, núms. 293 a 306: http://iump.ucm.es/DialogycaBDDH/BDDH293/la-escuela-de-los-sofistas/ y siguientes (última consulta 5-I-2018).

Henrichot, Michel (2005), «Le dialogue des morts au dix-huitième siècle: écarts et ornières d'une forme», Studies on Voltaire and the Eighteenth-Century, Oxford: Voltaire Foundation, pp. 153-162.

Instituto Cervantes (ed.) (2014), «Carmen de Burgos. Bibliografía», Dpto. de Bibliotecas y Documentación, en:

http://www.cervantes.es/imagenes/File/biblioteca/bibliografias/burgos carmen_bibliografia.pdf (última consulta el 13 septiembre 2016).

Lafarga, Francisco (1982), Voltaire en España (1734-1835), pról. Christoffer Todd, Barcelona: Edicions de la Universitat de Barcelona, D. L..

León, Ricardo (1920), «La sombra de Leopardi», en La escuela de los sofistas (Diálogo de apacible pasatiempo), Madrid: Editorial Pueyo, pp. 55-70.

Leopardi, Giacomo, cf. Burgos, Carmen de ([s.a.] 1911?).

Leopardi, Giacomo (1876), «Copernico», trad. de Juan O’Neille, en Museo Balear, Palma de Mallorca, II, 8, pp. 287-300.

----- (1878), «Diálogo de Malambruno y Farfarello», trad. de Federico Baráibar, en El Ateneo, Vitoria (enero).

---- (1878), «Copernico», trad. de Manuel de la Revilla con el título «Copernico: Diálogo humorístico de Giacomo Leopardi», en Revista Contemporánea, Madrid, 17 (sept.-oct.), pp. 326-336.

---- (1880), Opuscules et pensées, traduit de l'italien et précédé d'une préface par Auguste Dapples, Paris: Libr. Germer Baillière (Impr. Jules Boyer).
---- ([1883]), Diálogos filosóficos, traducidos y precedidos de una introducción crítico-biográfica por Luis Cánovas, Madrid: Librería Gutenberg (Imp. de la Revista de legislación), XXV, 105 págs).

---- (1899), «Diálogo entre un vendedor de almanaques y un transeunte», traducción anónima [¿de Luis Ruiz Contreras?], en Revista Nueva 1, 3, pp. 104-105.

---- (1917), Parini o De la gloria, trad. esp. Roberto F. Giusti, San José: Alsina.

---- (1959), Operette morali, [antología] en Canti, con una scelta da "Le Operette morali", "I pensieri", "Gli appunti", "Lo zibaldone”, a cura di Francesco Flora, Milano: Einaudi, con reed. electrónica de Letteratura italiana Einaudi.

---- (1979), Gedichte und Prosa: ausgewählte Werke, ausgewählt und übersetzt von Ludwig Wolde, Frankfurt am Main: Insel Verlag.

---- (1982), Operette Morali, introduzione, note e antologia della critica di Paolo Ruffilli, [Milano]: Garzanti.

---- (2000), Obritas morales. Diccionario Leopardiano, traducción, notas y compilación de Trinidad Blanco de García, Córdoba (Argentina): Centro de Italianística, Facultad de Lenguas, Universidad Nacional de CórdobaInstituto Italiano di Cultura de Córdoba.

---- (2013), Giacomo Leopardi: Tutte le poesie, tutte le prose e lo Zibaldone, eds. Lucio Felici (per la selezione poetica) e Emanuele Trevi (per la sezione della prosa), Roma: Newton Compton Editori.

---- (2015), Opúsculos morales, trad., introd. y notas por Alejandro Pablo Patat, Buenos Aires: Ediciones Colihue.

---- (2016), Diálogo entre la moda y la muerte y otras "Operette morali" de Giacomo Leopardi, traducción del italiano de Alicia Herrero Ansola, Madrid: Trama Editorial.

----- (2017), Diálogos morales: una investigación satírica y estética de las raíces de las miserias humanas, edición y traducción de Álvaro Otero, Madrid: Biblioteca Nueva.

UNED. REI, 6 (2018), pp. 37-87

ISSN 2340-9029 
Luciano (1889), Obras completas, trad. Federico Baráibar, Madrid: Librería de la Viuda de Hernando y Cía.. 3 vols.

Martín Murillo Ma Luisa (2014), «Carmen de Burgos, La voz de los muertos», BDDH 239 a 252, en DialogycaBDDH, asequibles en: http://iump. ucm.es/DialogycaBDDH/BDDH239/la-voz-de-los-muertos/ y siguientes (última consulta 19 julio 2016).

Martindale, Charles (2007), «Reception», en A Companion to the Classical Tradition, ed. Craig W. Kallendorf, Oxford: Blackwell Publishing, pp. 297311.

Mattioli, Emilio (2008), «Leopardi e Luciano», en Leopardi e il mondo antico, atti del $V$ convegno internazionale di studi leopardiani, ed. Centro nazionale di studi leopardiani, Firenze: Olschki, pp. 75-98.

Muñiz, Ma Nieves (2003), «Ensayo de un catálogo de las Traducciones españolas de obras literarias italianas en el siglo XIX», en Quaderns de Filologia. Estudis Lingüistics, VIII, pp. 93-150.

Núñez Rey, Concepción (1992), Carmen de Burgos "Colombine" (18671932): biografía y obra literaria, Madrid: Universidad Complutense-Servicio de Reprografía.

---- (2005), Colombine en la Edad de Plata de la literatura española, Sevilla: Fundación José Manuel Lara.

Parini, Giuseppe (1961), «Dialogo sopra la nobiltá», texto en «Poesie minori e Prose», Opere scelte, a cura di G. M. Zurardelli, Torino: UTET.

Platón (1992), Diálogos II. Gorgias. Menéxeno. Eutidemo. Menón. Crátilo, trad., intr. y notas de Julio Calonge Ruiz, E. Acosta Méndez, F. J. Olivieri y J. L. Calvo, Madrid: Gredos.

Polizzi, Gaspare (2008), «Spettacolo senza spettatore. Dalla 'pietade illuminata' al Dialogo di un Folletto e di uno Gnomo", en su "...per le forze eterne della materia”. Natura e scienza in Giacomo Leopardi, Milano: Franco Angeli, pp. 55-102.

Pujol, Stéphane (2005), Le dialogue d'idées au dix-huitième siècle, Oxford: Voltaire Foundation.
Renan, Ernest (1925), Dialogues philosophiques [1871], Paris: Claude Aveline Éditeur.

Robinson, Christopher (1979), Lucian and his influence in Europe, London: Duckworth.

Rodríguez Domínguez, Sandalio (1979), Renacimiento universitario salmantino a finales del siglo XVIII. Ideología liberal del Dr. Ramón de Salas y Cortés, Salamanca: Universidad de Salamanca.

Rodríguez Villa, Antonio (1875), Memorias para la historia del asalto y saqueo de Roma en 1527 por el ejército imperial, formadas con documentos originales, cifrados e inéditos en su mayor parte, Madrid: Imprenta de la Biblioteca de Instrucción y Recreo.

---- (1885), Italia desde la batalla de Pavía hasta el saco de Roma, Madrid: L. Navarro.

Sáez Rivera, Daniel (2015), «Un gramático, ortógrafo, lexicógrafo, poeta, periodista, traductor y cervantista olvidado de principios del siglo XIX: Manuel Lozano Pérez Ramajo», en Censuras, exclusiones y silencios en la historia de la lingüística hispánica, eds. María Luisa Calero y Carlos Subirats, Estudios de Lingüística del Español (ELiEs/IR), 36, pp. 95-160.

Sainz de Robles, Federico Carlos (1975), La promoción de 'El Cuento semanal', Madrid: Austral.

Sangirardi, Giuseppe (1998), «Luciano dalle 'prosette satiriche' alle Operette Morali», en Il riso leopardiano: comico, satira, parodia, atti del IX convegno internazionale di studi leopardiani (Recanati, 18-22 settembre 1995), ed. Rolando Garbuglia, Firenze: Olschki, pp. 305-383.

---- (2001), Il libro dellesperienza e il libro della sventura, Roma: Bulzoni, pp. 25-86.

Scheel, Hans Ludwig (1998), «Leopardi e i satirici greci e latini», en Il riso leopardiano: comico, satira, parodia, atti del IX convegno internazionale di studi leopardiani (Recanati, 18-22 settembre 1995), ed. Rolando Garbuglia, Firenze: Olschki, pp. 25-31.

Sigurðsson, Geir (2010), «In Praise of Illusions. Giacomo Leopardi’s Ultraphilosophy», Nordicum-Meditteraneum, 5, 1, asequible en: http://nome. 
unak.is/nm-marzo-2012/5-1x/11-articles51/42-in-praise-of-illusionsgiacomo-leopardis-ultraphilosophy (fecha de consulta: 1 junio 2017).

Simón Palmer, Ma Carmen (1991), Escritoras españolas del siglo XIX: Manual biobibliográfico, Madrid, Castalia.

----- (2016), «Carmen de Burgos (1867-1932): el valor de una traductora», en Retratos de traductoras en la Edad de Plata, ed. e intr.. Dolores Romero López, Madrid: Escolar y Mayo Editores, pp. 41-59.

Timpanaro, Sebastiano (1979), «The Pessimistic Materialism of Giacomo Leopardi», New Left Review I, 116 (jul-aug.), (https://newleftreview. org/I/116/sebastiano-timpanaro-the-pessimistic-materialism-of-giacomo-leopardi, fecha de consulta: 8 diciembre 2015).

Trapnell, William (1972), Voltaire and his portable Dictionary, Frankfurt: Klostermann.

Utrera, Federico (1998), Memorias de Colombine: La primera periodista, Majadahonda (Madrid): Ediciones HMR (Hijos de Muley-Rubio).

Valdés, Alfonso de (1928), Diálogo de las cosas ocurridas en Roma, ed. José F. Montesinos, Madrid: La Lectura.

Vian Herrero, Ana (2011), estudio preliminar a Antonio Rodríguez Villa, Memorias para el asalto y saqueo de Roma. El relato documental del asalto y saqueo de Roma en 1527, Córdoba: Almuzara, pp. xiii-lx.

Vitale, Maurizio (1992), La lingua della prosa di G. Leopardi: le "Operette morali”, Firenze: La Nuova Italia.

Voltaire (1781), Historia de Carlos XII, rey de Suecia, traducción de Leonardo de Uría y Orueta, Madrid: en la Imprenta de Don Pedro Marín.

---- (1786), Euvres complètes. Dialogues. Vol. XXXVI, Basle: de l'Imprimerie de Jean-Jaques Tourneisen.

---- (1818), Euvres complètes, Paris: Chez P. Plancher (Imprimerie de Mme. Jeunehomme).

---- ([s.a.], pero 1901), Diccionario filosófico, Valencia: Prometeo.

---- (1935), Diccionario filosófico, ed. Juan B. Bergua, Madrid: Clásicos Bergua.

----- (1996), Diálogo de Evémero, trad. Mauro Armiño, Madrid: Valdemar.
----- (2010), Voltaire I, introd. Martí Domínguez, trad. F. Savater, C. R. Dampierre, L. Martínez Drake, M. Armiño, Madrid: Gredos, pp. i-xcviii.

---- (2015), François Marie Arouet, Diálogos, ed. Jaime Rosal, Barcelona: Sd ediciones.

Weinbrot, Howard D. (2005), Menippean Satire reconsidered: from Antiquity to the Eighteenth Century, Baltimore: The Johns Hopkins University Press

Zuber, Roger (1997), «De Lucien écrivain au Lucien de d'Ablancourt», Les Émerveillements de la raison, Paris: Klincksieck, pp. 181-188. 